\title{
On the gamma spectrum of multiplication gamma acts
}

\author{
Mehdi S. Abbas ${ }^{1}$, Samer A. Gubeir, ${ }^{2, *}$ \\ ${ }^{1}$ Dept. of Mathematics, College of Education, Al-Zahraa University for women, Iraq \\ ${ }^{2}$ Dept. of Air Conditioning and Refrigeration Techniques Engineering, Al-Mustaqbal University \\ College, Iraq \\ *Corresponding author: samer.adam@mustaqbal-college.edu.iq
}

\begin{abstract}
In this paper, we introduce the concept of topological gamma acts as a generalization of Zariski topology. Some topological properties of this topology are studied. Various algebraic properties of topological gamma acts have been discussed. We clarify the interplay between this topological space's properties and the algebraic properties of the gamma acts under consideration. Also, the relation between this topological space and (multiplication, cyclic) gamma act was discussed. We also study some separation axioms and the compactness of this topological space.
\end{abstract}

Keywords: Gamma spectrum; multiplication gamma acts; prime gamma subact; radical gamma subact; topological gamma acts.

\section{Introduction}

In 1981, Sen, M. (Sen, 1981) introduced the concept of gamma semigroups as a generalization of semigroups as follows: let $\mathrm{S}$ and $\Gamma$ be nonempty sets, $\mathrm{S}$ is said to be a gamma semigroup ( $\Gamma$-semigroup for short) if there is a mapping: $\mathrm{S} \times \Gamma \times \mathrm{S} \rightarrow \mathrm{S}$ written $\left(s_{1}, \alpha, s_{2}\right)$ by $s_{1} \alpha s_{2}$ that satisfies the condition $s_{1} \alpha\left(s_{2} \beta s_{3}\right)=\left(s_{1} \alpha s_{2}\right) \beta s_{3}$ for all $s_{1}, s_{2}, s_{3} \in$ $\mathrm{S}$ and $\alpha, \beta \in \Gamma$. Let $\mathrm{S}$ be a $\Gamma$-semigroup. An element $s \in \mathrm{S}$ is called the left (right) identity of $\mathrm{S}$ if $s \alpha t=t(t \alpha s=t)$ for all $t \in S$ and $\alpha \in \Gamma$. An element $s$ in $\mathrm{S}$ is called identity if it is both a left and right identity of $\mathrm{S}$. A $\Gamma$-semigroup with identity is called a $\Gamma$-monoid. The identity of a $\Gamma$-semigroup (if exists) is denoted by 1 . A $\Gamma$-semigroup $\mathrm{S}$ is called commutative if $s \alpha t=t \alpha s$ for all $s, t \in \mathrm{S}$ and $\alpha \in \Gamma$. A nonempty subset $\mathrm{T}$ of $\Gamma$-semigroup $\mathrm{S}$ is called a $\Gamma$-subsemigroup of $\mathrm{S}$ if $s \alpha t \in \mathrm{T}$, for all $s, t \in \mathrm{T}$ and $\alpha \in \Gamma$. A nonempty subset $A$ of semigroup $S$ is called left (right) $\Gamma$-ideal if $\mathrm{S} \Gamma \mathrm{A} \subseteq \mathrm{A}$ $(\mathrm{A} \Gamma \mathrm{S} \subseteq \mathrm{A})$ where $\mathrm{S} \Gamma \mathrm{A}=\{s \alpha a: s \in S, \alpha \in$ $\Gamma$ and $a \in A\}$. The word $\Gamma$-ideal is used for a two-sided $\Gamma$-ideal. The union of any family of $\Gamma$-ideals of $\Gamma$-semigroup $S$ is a $\Gamma$-ideal of
$\mathrm{S}$ (Sen, 1981). An element $s \in \mathrm{S}$ is said to be $\alpha$-idempotent if there exists $\alpha \in \Gamma$ such that $s \alpha s=s$. A $\Gamma$-semigroup $\mathrm{S}$ is called idempotent if all elements of $S$ are $\alpha$-idempotent. For any subsets $\mathrm{A}$ and $\mathrm{B}$ of $\mathrm{S}$, then, $\mathrm{A} \Gamma \mathrm{B}=\{a \alpha b: a$ $\in \mathrm{A}, b \in \mathrm{B}$, and $\alpha \in \Gamma\}$. A $\Gamma$-ideal B of a $\Gamma$ semigroup $\mathrm{S}$ is called globally idempotent (gl-idempotent for short) if $\mathrm{B} \Gamma \mathrm{B}=\mathrm{B}$ (Anjaneyulu et al., 2012). A $\Gamma$-ideal $\mathrm{P}$ of $\mathrm{S}$ is said to be prime provided that for any two $\Gamma$-ideals $\mathrm{A}, \mathrm{B}$ of $\mathrm{S}$ with $\mathrm{A} \Gamma \mathrm{B} \subseteq \mathrm{P}$, either $\mathrm{A}$ $\subseteq \mathrm{P}$ or $\mathrm{B} \subseteq \mathrm{P}$ (Anjaneyulu et al., 2011). A $\Gamma$-ideal $\mathrm{B}$ of a $\Gamma$-semigroup $\mathrm{S}$ is called maximal if it is proper and is not properly contained in any proper $\Gamma$-ideal of $S$ (Anjaneyulu et al., 2012). In 2016, Abbas M. and Faris A. (Abbas \& Faris, 2016) introduced gamma's concept over gamma semigroup as follows: let $\mathrm{S}$ be a $\Gamma$ semigroup. A nonempty set $\mathrm{M}$ is called left gamma act over $\mathrm{S}$ (denoted by $\mathrm{S}_{\Gamma}$-act) if there is a mapping: $\mathrm{S} \times \Gamma \times \mathrm{M} \rightarrow \mathrm{M}$ defined by $(s, \alpha, m) \mapsto s \alpha m$, satisfying $\left(s_{1} \alpha s_{2}\right) \beta m$ $=s_{1} \alpha\left(s_{2} \beta m\right)$ for all $s_{1}, s_{2} \in \mathrm{S}, \alpha, \beta \in \Gamma$ and $m \in M$. In the same way, we can define right gamma acts. From now on, "S $\mathrm{S}_{\Gamma}$-act" means left $\mathrm{S}_{\Gamma}$-act. A nonempty 
subset $\mathrm{N}$ of a left $\mathrm{S}_{\Gamma}$-act $\mathrm{M}$ is called gamma subact (denoted by $\mathrm{S}_{\Gamma}$-subact) if, for all $s \in$ $S, \alpha \in \Gamma$ and $n \in \mathrm{N}$ implies that $s \alpha n \in \mathrm{N}$. An element $\theta \in M$ is called a zero of $M$ if $s \alpha \theta=\theta$, and if $\mathrm{S}$ is a $\Gamma$-semigroup with zero then, $0 \alpha m=\theta$ for all $m \in \mathrm{M}$ and $\alpha \in \Gamma$. Let $\mathrm{N}$ be a $\mathrm{S}_{\Gamma}$-subact of $\mathrm{S}_{\Gamma}$-act $\mathrm{M}$. Then, $[\mathrm{N}: \mathrm{M}]=\{s \in S \mid s \alpha m \in \mathrm{N}$ for all $\alpha \in \Gamma$ and $m \in \mathrm{M}\}$. Clearly, [N: M] is a $\Gamma$-ideal of S. Given a family of $\mathrm{S}_{\Gamma}$-subacts $\left\{\mathrm{N}_{i}\right\}_{i \in \mathrm{I}}$ of $\mathrm{S}_{\Gamma}$-act $\mathrm{M}$. Then, $\mathrm{U}_{i \in I} \mathrm{~N}_{\mathrm{i}}$ is $\mathrm{S}_{\Gamma}$-subact of $\mathrm{M}$, and if $\bigcap_{i \in I} \mathrm{~N}_{i}$ is nonempty, then, $\bigcap_{i \in \mathrm{I}} \mathrm{N}_{i}$ is $\mathrm{S}_{\Gamma^{-}}$ subact of $\mathrm{M}$. Let $\mathrm{M}$ and $\mathrm{N}$ be two $\mathrm{S}_{\Gamma}$-acts. $\mathrm{A}$ mapping $f: \mathrm{M} \rightarrow \mathrm{N}$ is called $\mathrm{S}_{\Gamma}$-homomorphism if $f(s \alpha m)=s \alpha f(m)$ for every $s \in \mathrm{S}, \alpha \in \Gamma$ and $m \in \mathrm{M}$. If $f$ is surjective, then, $f$ is $\mathrm{S}_{\Gamma^{-}}$ epimorphism. Let $f: \mathrm{M} \rightarrow \mathrm{N}$ be $\mathrm{S}_{\Gamma}$-homomophism. Then, the kernel $f$ is defined as $\operatorname{ker}(f)=\left\{\left(m_{1}, m_{2}\right) \in \mathrm{M} \times \mathrm{M} \mid f\left(m_{1}\right)=f\left(m_{2}\right)\right\}$ (Kamal, 2016). An equivalence relation $\rho$ on $\mathrm{S}_{\Gamma}$-act $\mathrm{M}$ is called a congruence if for all $\left(m_{1}, m_{2}\right) \in \rho$ implies that $\left(s \alpha m_{1}, s \alpha m_{2}\right) \in \rho$ for all $s \in S, \alpha \in \Gamma$. Also, the quotient gamma act of the congruence $\rho$ on $\mathrm{M}$ is denoted by $\mathrm{M} / \rho$ define by $\mathrm{M} / \rho=\{m \rho \mid m \in \mathrm{M}$ and $m \rho$ the equivalent class containing $m\}$.

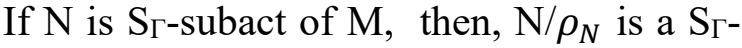
subact of $\mathrm{M} / \rho$ where $\rho_{N}=\rho \cap(\mathrm{N} \times \mathrm{N})$. If $\mathrm{H}$ is a nonempty subset of $\mathrm{S}_{\Gamma}$-act $\mathrm{M}$, then, $\ell_{\mathrm{S}}(\mathrm{H})=\{(s, t) \in \mathrm{S} \times \mathrm{S} \mid s \alpha h=t \alpha h$ for all $\alpha \in \Gamma$ and $h \in \mathrm{H}$ \}. It is known that $\ell_{\mathrm{S}}(\mathrm{H})$ is a congruence on $\mathrm{S}_{\Gamma}$-act $\mathrm{S}$ (Kamal, 2016). Recently, Abbas M. and Jubeir S. (Abbas \& Jubeir, 2020) introduced the concept of multiplication gamma acts. An $\mathrm{S}_{\Gamma}$-act $\mathrm{M}$ is said to be a multiplication if every $\mathrm{S}_{\Gamma^{-}}$-subact $\mathrm{N}$ of $\mathrm{M}$ is of the form $\mathrm{N}=\mathrm{A} \Gamma \mathrm{M}$ for some $\Gamma$ ideal $\mathrm{A}$ of $\mathrm{S}$. An $\mathrm{S}_{\Gamma}$-act $\mathrm{M}$ is multiplication if and only if $\mathrm{N}=[\mathrm{N}: \mathrm{M}] \Gamma \mathrm{M}$ for all $\mathrm{S}_{\Gamma}$-subact $\mathrm{N}$ of $\mathrm{M}$. Let $\mathrm{M}$ be a $\mathrm{S}_{\Gamma}$-act and $s_{1}, s_{2} \in \mathrm{S}$. Then, $\mathrm{M}$ is called faithful if the equality $s_{1} \alpha m=s_{2} \alpha m$ implies that $s_{1}=s_{2}$ for every $m \in \mathrm{M}$ and $\alpha \in \Gamma$. Let $\mathrm{S}$ be a commutative $\Gamma$-monoid and $\mathrm{M}$ be a faithful $\mathrm{S}_{\Gamma}$-act. Then, $M$ is a multiplication if and only if $\bigcap_{i \in \mathrm{I}}\left(\mathrm{A}_{i} \Gamma \mathrm{M}\right)=\left(\bigcap_{i \in \mathrm{I}} \mathrm{A}_{i}\right) \Gamma \mathrm{M}$ for any nonempty collection of $\Gamma$-ideals $\mathrm{A}_{i}, i \in \mathrm{I}$ of $\mathrm{S}$, and for all $\mathrm{S}_{\Gamma}$-subact $\mathrm{N}$ of $\mathrm{M}$ and $\Gamma$-ideal $\mathrm{A}$ of $\mathrm{S}$ such that $\mathrm{N} \subset \mathrm{A} \Gamma \mathrm{M}$ there exists an $\Gamma$-ideal $\mathrm{B}$ with $\mathrm{B} \subset \mathrm{A}$ and $\mathrm{N} \subseteq \mathrm{B} \Gamma \mathrm{M}$. Let $\mathrm{A}$ be a $\Gamma$ - ideal of $\Gamma$-monoid $\mathrm{S}$, and $\mathrm{M}$ be a $\mathrm{S}_{\Gamma}$-act. If $\mathrm{M}$ is faithful multiplication, then, $\mathrm{A}=[\mathrm{A} \Gamma \mathrm{M}: \mathrm{M}]$ (Abbas \& Jubeir, 2020). Let $\mathrm{N}_{1}, \mathrm{~N}_{2}$ be $\mathrm{S}_{\Gamma^{-}}$ subacts of multiplication $\mathrm{S}_{\Gamma}$-act $\mathrm{M}$. If $\mathrm{N}_{1}=\mathrm{A} \Gamma \mathrm{M}$ and $\mathrm{N}_{2}=\mathrm{B} \Gamma \mathrm{M}$ for some $\Gamma$-ideals $\mathrm{A}$ and $\mathrm{B}$ of $\mathrm{S}$, then the product of $\mathrm{N}_{1}$ and $\mathrm{N}_{2}$ is denoted by $\mathrm{N}_{1} * \mathrm{~N}_{2}$ is defined by $\mathrm{N}_{1} * \mathrm{~N}_{2}=($ АГВ) $\Gamma \mathrm{M}$. Clearly, $\mathrm{N}_{1} * \mathrm{~N}_{2}$ is an $\mathrm{S}_{\Gamma}$-subact of M. Let $\mathrm{N}$ be a $\mathrm{S}_{\Gamma}$-subact of multiplication $\mathrm{S}_{\Gamma}$-act $\mathrm{M}$. Then, $\mathrm{N}$ is called gamma nilpotent $(\Gamma$-nilpotent for short) if $\mathrm{N}^{k}=\theta$ for some positive integer $k$, where $\mathrm{N}^{k}$ means the product of $\mathrm{N}, k$ times. (Abbas \& Adnan, 2020).

For $\mathrm{S}_{\Gamma-\text {-act }} \mathrm{M}$, the set of all prime $\mathrm{S}_{\Gamma^{-}}$ subacts of $\mathrm{M}$ is called the gamma spectrum of $\mathrm{M}$ and denoted by $\operatorname{Spec}_{\Gamma}(\mathrm{M})$. We remark that $\operatorname{Spec}_{\Gamma}(\theta)=\varnothing$ and that $\operatorname{Spec}_{\Gamma}(\mathrm{M})$ may be empty; for example, the zero $\mathrm{S}_{\Gamma}$-act has no prime $\mathrm{S}_{\Gamma}$-subact. Throughout this paper, we assume that $\operatorname{Spec}_{\Gamma}(\mathrm{M})$ is nonempty. This article aims to study topological gamma acts for which the gamma spectrum is a topology in which the varieties $V_{\Gamma}(\mathrm{N})=\left\{\mathrm{P} \in \operatorname{Spec}_{\Gamma}(\mathrm{M}): \mathrm{N} \subseteq \mathrm{P}\right\}$ are closed sets for any $\mathrm{S}_{\Gamma}$-subacts $\mathrm{N}$ of the $\mathrm{S}_{\Gamma}$-act $\mathrm{M}$. Note that our definition is a generalization of the Zariski topology on the spectrum of prime ideals of a ring. Thus, we extend the wellknown results of Zariski topology on $\operatorname{Spec}(R)$ to $\operatorname{Spec}_{\Gamma}(\mathrm{M})$ and investigate the basic properties of this topology. The concepts of semiprime and extraordinary $\mathrm{S}_{\Gamma}$-subacts are introduced to identify some cases when the gamma spectrum of a gamma act forms a topology. Also, using the concept of multiplication gamma acts to investigate various algebraic properties of such topology. We prove that $\operatorname{Spec}_{\Gamma}(\mathrm{M})$ is a $\mathrm{T}_{0}$-space and it is compact if $\mathrm{M}$ is finitely generated multiplication gamma act. The relationship between $\operatorname{Spec}_{\Gamma}(\mathrm{M})$ and $\operatorname{Spec}_{\Gamma}(\mathrm{S})$ was investigated.

\section{Preliminaries}

In this section we introduce the concept of prime gamma subacts and basic related concepts which are needed in our work.

\subsection{Definition.}

A proper $\mathrm{S}_{\Gamma}$-subact $\mathrm{N}$ of $\mathrm{M}$ is prime if for any $m \in \mathrm{M}$ and $s \in \mathrm{S}$, the set inclusion 
$s \Gamma \mathrm{S} \Gamma m \subseteq \mathrm{N}$ implies either $m \in \mathrm{N}$ or $s \in$ [N:M].

\subsection{Example.}

Let $\mathrm{S}=\{\varnothing,\{\mathrm{a}\},\{\mathrm{b}\},\{\mathrm{c}\},\{\mathrm{a}, \mathrm{b}\},\{\mathrm{b}, \mathrm{c}\},\{\mathrm{a}, \mathrm{c}\}$, $\{\mathrm{a}, \mathrm{b}, \mathrm{c}\}\}, \Gamma=\{\varnothing,\{\mathrm{a}\},\{\mathrm{a}, \mathrm{b}, \mathrm{c}\}\}$ and $\mathrm{M}=\mathrm{S}$. Then, $\mathrm{M}$ is a $\mathrm{S}_{\Gamma}$-act under the mapping: $\mathrm{S} \times \Gamma \times \mathrm{M} \rightarrow \mathrm{M}$ defined by $(\mathrm{A}, \mathrm{B}, \mathrm{C}) \mapsto \mathrm{A} \cap \mathrm{B} \cap \mathrm{C}$. It can be easily verified that the $\mathrm{S}_{\Gamma}$-subact $\{\{\mathrm{a}, \mathrm{b}\},\{\mathrm{a}\}, \emptyset\}$ is a prime $\mathrm{S}_{\Gamma}$-subact of $\mathrm{M}$.

\subsection{Proposition.}

Let $\mathrm{S}$ be a commutative $\Gamma$-semigroup and $\mathrm{N}$ be a proper $\mathrm{S}_{\Gamma-\text { subact }}$ of $\mathrm{S}_{\Gamma-\text { act }} \mathrm{M}$. The following statements are equivalent:

i. For every $\mathrm{S}_{\Gamma}$-subact $\mathrm{K}$ of $\mathrm{M}$, if $\mathrm{N} \subset \mathrm{K}$, then, $[\mathrm{N}: \mathrm{M}]=[\mathrm{N}: \mathrm{K}]$.

ii. $\mathrm{N}$ is prime.

Proof:(i) $\Longrightarrow$ (ii) Let $s \in \mathrm{S}$ and $m \in \mathrm{M}$, such that $s \Gamma \mathrm{S} \Gamma m \subseteq \mathrm{N}$ and $m \notin \mathrm{N}$. It is clear that $\mathrm{N} \subset \mathrm{N} U \mathrm{~S} \Gamma m$. Since $s \Gamma(\mathrm{NUS} \Gamma m) \subseteq s \Gamma \mathrm{N}$ $\mathrm{U} s \Gamma(\mathrm{S} \Gamma m) \subseteq \mathrm{N}$. By statement (i), $s \in[\mathrm{N}: \mathrm{NU}$ $\mathrm{S} \Gamma m]=[\mathrm{N}: \mathrm{M}]$.

(ii) $\Rightarrow$ (i) Let $\mathrm{K}$ be a $\mathrm{S}_{\Gamma}$-subact of $\mathrm{M}$ such that $\mathrm{N} \subset \mathrm{K}$. Clearly $[\mathrm{N}: \mathrm{M}] \subseteq[\mathrm{N}: \mathrm{K}]$. Now, suppose that $s \in[\mathrm{N}: \mathrm{K}]$. Then, $s \Gamma \mathrm{S} \Gamma \mathrm{K} \subseteq s \Gamma \mathrm{K} \subseteq \mathrm{N}$. Since $\mathrm{N} \subset \mathrm{K}$, then, there exists $k \in \mathrm{K} \backslash \mathrm{N}$ such that $s \Gamma S \Gamma k \subseteq \mathrm{N}$. By statement(ii), $s \in[\mathrm{N}: \mathrm{M}]$. Hence, $[\mathrm{N}: \mathrm{M}]=[\mathrm{N}: \mathrm{K}]$.

\subsection{Proposition.}

Let $\mathrm{S}$ be a commutative $\Gamma$-monoid, and $\mathrm{M}$ be a multiplication $\mathrm{S}_{\Gamma^{-}}$-act. Then, for any $\mathrm{S}_{\Gamma^{-}}$ subact $\mathrm{N}$ of $\mathrm{M}$, the following conditions are equivalent:

i. $\mathrm{N}$ is prime $\mathrm{S}_{\Gamma}$-subact of $\mathrm{M}$.

ii. $[\mathrm{N}: \mathrm{M}]$ is prime $\Gamma$-ideal of $\Gamma$-semigroup $\mathrm{S}$. iii. There exists a prime $\Gamma$-ideal $\mathrm{P}$ of $\mathrm{S}$, which is maximal with the property $\mathrm{P} \Gamma \mathrm{M}=\mathrm{N}$.

Proof: (i) $\Rightarrow$ (ii) Let $A, B$ be $\Gamma$-ideals of $S$. Consider the inclusion $\mathrm{A} \Gamma \mathrm{B} \subseteq[\mathrm{N}: \mathrm{M}]$.Then, $(\mathrm{A} Г \mathrm{~B}) \Gamma \mathrm{M} \subseteq \mathrm{N}$. Now, assume $\mathrm{A} \nsubseteq[\mathrm{N}: \mathrm{M}]$ then there is $a \notin[\mathrm{N}: \mathrm{M}]$ such that a $\alpha x \notin \mathrm{N}$, for some $x \in \mathrm{M}$ and $\alpha \in \Gamma$. Let $\mathrm{b} \in \mathrm{B}$, then, $\mathrm{b} \Gamma(a \alpha x)=(b \Gamma a) \alpha x=(a \Gamma b) \alpha x \subseteq \mathrm{N}$. Since $\mathrm{N}$ is a prime $\mathrm{S}_{\Gamma}$-subact of $\mathrm{M}$ and $a \alpha x \notin \mathrm{N}$, then, $\mathrm{b} \Gamma \mathrm{M} \subseteq \mathrm{N}$. Thus, $[\mathrm{N}: \mathrm{M}]$ is prime. (ii) $\Rightarrow$ (iii) Consider the family of $\Gamma$-ideals $\mathrm{T}=\{\mathrm{P}: \mathrm{N}=\mathrm{P} \Gamma \mathrm{M}$ and $\mathrm{P}$ is an $\Gamma$-ideal of $\mathrm{S}\}$. Since $\mathrm{M}$ is multiplication $\mathrm{S}_{\Gamma}$-act, then, $\mathrm{T}$ is a nonempty partial order set by the usual inclusion relation. Let $\left\{\mathrm{P}_{i}\right\}_{i \in \mathrm{I}} \subseteq \mathrm{T}$ be a chain. Then, $\bigcup_{i \in \mathrm{I}} \mathrm{P}_{i} \in \mathrm{T}$ is an upper bound of $\left\{\mathrm{P}_{i}\right\}_{i \in \mathrm{I}}$. Zorn's Lemma implies that $\mathrm{T}$ has a maximal element such as $\mathrm{P}$ (say). Now, let $\mathrm{A}$ and $\mathrm{B}$ be two $\Gamma$-ideals such that $\mathrm{A} \Gamma \mathrm{B} \subseteq \mathrm{P}$, then, $(\mathrm{A} Г \mathrm{~B}) \Gamma \mathrm{M} \subseteq \mathrm{P} \Gamma \mathrm{M} \subseteq \mathrm{N}$ and hence we obtain $\mathrm{A} \Gamma \mathrm{B} \subseteq[\mathrm{N}: \mathrm{M}]$, but by the assumption that $[\mathrm{N}: \mathrm{M}]$ is prime we conclude that either $\mathrm{A} \subseteq[\mathrm{N}: \mathrm{M}] \subseteq \mathrm{P}$ or $\mathrm{B} \subseteq[\mathrm{N}: \mathrm{M}] \subseteq \mathrm{P}$. Thus $\mathrm{P}$ is prime $\Gamma$-ideal of $\mathrm{S}$.

(iii) $\Rightarrow$ (i) Let $\mathrm{P}$ be a prime $\Gamma$-ideal of $\mathrm{S}$, which is maximal with the property $\mathrm{P} \Gamma \mathrm{M} \subseteq \mathrm{N}$. Clearly, $\mathrm{P}=[\mathrm{N}: \mathrm{M}]$. Let $x \in \mathrm{S}$ and $m \in \mathrm{M}$ such that $x \Gamma \mathrm{S} \Gamma m \subseteq \mathrm{N}$. Since $\mathrm{M}$ is a multiplication, then there exists a $\Gamma$-ideal $A$ of $\mathrm{S}$, such that $\mathrm{S} \Gamma m=\mathrm{A} \Gamma \mathrm{M}$, and hence $x \Gamma(\mathrm{A} \Gamma \mathrm{M})=x \Gamma \mathrm{S} \Gamma m$ $\subseteq \mathrm{N}$. Thus $x \Gamma \mathrm{A} \subseteq[\mathrm{N}: \mathrm{M}]$. Since $[\mathrm{N}: \mathrm{M}]=\mathrm{P}$ and $\mathrm{P}$ is prime $\Gamma$-ideal of $\mathrm{S}$, then, $x \in[\mathrm{N}: \mathrm{M}]$ or $\mathrm{A} \subseteq[\mathrm{N}: \mathrm{M}]$ i.e $x \in[\mathrm{N}: \mathrm{M}]$ or $m \in \mathrm{S} \Gamma m=\mathrm{A} \Gamma \mathrm{M}$

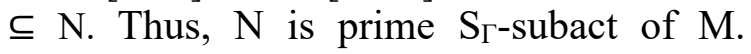

\subsection{Proposition.}

Let $\mathrm{N}$ be a proper $\mathrm{S}_{\Gamma}$ subac of $\mathrm{S}_{\Gamma}$-act $\mathrm{M}$. Then, $\mathrm{N}$ is a prime in $\mathrm{M}$ if and only if $\mathrm{N} / \rho_{N}$ is prime $\mathrm{S}_{\Gamma}$-subact of $\mathrm{S}_{\Gamma-\text {-act }} \mathrm{M} / \rho$.

Proof: $\Rightarrow$ Let $s \in \mathrm{S}$ and $m \rho \in \mathrm{M} / \rho$ where $m \in$ M satisfy $s \Gamma \mathrm{S} \Gamma(m \rho) \subseteq \mathrm{N} / \rho_{N}$. Thus $(s \alpha t \beta m) \rho$ $=s \alpha t \beta(m \rho) \in \mathrm{N} / \rho_{N}$ for all $t \in \mathrm{S}$ and $\alpha, \beta \in \Gamma$. This implies that $s \alpha t \beta m \subseteq \mathrm{N}$. By hypothesis ,$s \Gamma \mathrm{M} \subseteq \mathrm{N}$ or $m \subseteq \mathrm{N}$. Thus, $s \Gamma(\mathrm{M} / \rho)=s \Gamma \mathrm{M} / \rho \subseteq$ $\mathrm{N} / \rho_{N}$ or $m \rho \in \mathrm{N} / \rho_{N}$.

$(\Leftarrow)$ Let $s \in \mathrm{S}$ and $m \in \mathrm{M}$ such that $s \Gamma \mathrm{S} \Gamma m \subseteq \mathrm{N}$. Then, $s \alpha t \beta m \in \mathrm{N}$ for all $t \in \mathrm{S}$ and $\alpha, \beta \in \Gamma$. So, $\operatorname{s\alpha t} \beta\left(m \rho_{N}\right)=(\operatorname{s\alpha t} \beta m) \rho_{N}$ $\in \mathrm{N} / \rho_{N}$. It follows that by assumption $s \in$ $\left[\mathrm{M} / \rho: \mathrm{N} / \rho_{N}\right]$ or $m \rho_{N} \in \mathrm{N} / \rho_{N}$. Thus, $s \Gamma \mathrm{M} / \rho$ $\subseteq \mathrm{N} / \rho_{N}$ or $m \in \mathrm{N}$. Hence, $s \gamma m_{\circ} \in \mathrm{N}$ for all $m \circ \in \mathrm{M}$ and $\gamma \in \Gamma$. Thus, $s \Gamma \mathrm{M} \subseteq \mathrm{N}$ or $m \in \mathrm{N}$.

\subsection{Proposition.}

Let $\left\{\mathrm{N}_{i}, i \in \mathrm{I}\right\}$ be a non-empty collection of $\mathrm{S}_{\Gamma}$-subacts of $\mathrm{S}_{\Gamma}$-act $\mathrm{M}$. 
If $\mathrm{N}_{i}$ is a prime $\mathrm{S}_{\Gamma}$-subacts for each $i \in \mathrm{I}$, then, $U_{i \in \mathrm{I}} \mathrm{N}_{i}$ is a prime $\mathrm{S}_{\Gamma}$-subact of $\mathrm{M}$. Proof: Let $s \in \mathrm{S}$ and $m \in \mathrm{M}$ satisfy $s \Gamma \mathrm{S} \Gamma m$ $\subseteq \bigcup_{i \in \mathrm{I}} \mathrm{N}_{i}$. Then, $s \Gamma \mathrm{S} \Gamma m \subseteq \mathrm{N}_{j}$ for some $j \in \mathrm{I}$. By hypothesis, either $s \in\left[\mathrm{N}_{j}: \mathrm{M}\right]$ or $m \in \mathrm{N}_{j}$. So, $s \in\left[\bigcup_{i \in \mathrm{I}} \mathrm{N}_{i}: \mathrm{M}\right]$ or $m \in \bigcup_{i \in \mathrm{I}} \mathrm{N}_{i}$ and hence $\bigcup_{i \in \mathrm{I}} \mathrm{N}_{i}$ is a prime $\mathrm{S}_{\Gamma-\text { subact. }}$

In the following, we characterize prime $\mathrm{S}_{\Gamma}$ - subact in multiplication $\mathrm{S}_{\Gamma}$-act by product $\mathrm{S}_{\Gamma-}$ subacts.

\subsection{Theorem}

Let $\mathrm{S}$ be a $\Gamma$-monoid and $\mathrm{P}$ be a proper $\mathrm{S}_{\Gamma^{-}}$ subact of a multiplication $\mathrm{S}_{\Gamma}$-act $\mathrm{M}$. Then $\mathrm{P}$ is prime if and only if $\mathrm{N}_{1} * \mathrm{~N}_{2} \subseteq \mathrm{P}$ then either $\mathrm{N}_{1} \subseteq \mathrm{P}$ or $\mathrm{N}_{2} \subseteq \mathrm{P}$ for each $\mathrm{S}_{\Gamma^{-}}$ subacts $\mathrm{N}_{1}, \mathrm{~N}_{2}$ of $\mathrm{M}$.

Proof: $(\Longrightarrow)$ Let $\mathrm{P}$ be a prime and $\mathrm{N}_{1} * \mathrm{~N}_{2} \subseteq \mathrm{P}$, but neither $\mathrm{N}_{1} \nsubseteq \mathrm{P}$ nor $\mathrm{N}_{2} \nsubseteq \mathrm{P}$ for some $\mathrm{S}_{\Gamma^{-}}$ subacts $N_{1}, N_{2}$ of $M$. Since $M$ is a multiplication, then $\mathrm{N}_{1}=\mathrm{A} \Gamma \mathrm{M}$ and $\mathrm{N}_{2}=\mathrm{B} \Gamma \mathrm{M}$ for some $\Gamma$-ideals $A, B$ of $S$. So there is $\mathrm{a} \in \mathrm{A}$ , $\mathrm{b} \in \mathrm{B}$ and $\alpha, \beta \in \Gamma$ such that $\mathrm{a} \alpha m \in \mathrm{N}_{1} \backslash \mathrm{P}$ and $\mathrm{b} \beta m^{\prime} \in \mathrm{N}_{2} \backslash \mathrm{P}$. Since (АГВ) $\Gamma \mathrm{M} \subseteq \mathrm{P}$. Thus $\mathrm{a} \alpha$ $\left(\mathrm{b} \beta m^{\prime}\right) \in \mathrm{P}$, and since $\mathrm{P}$ is prime then either $\mathrm{a} \in[\mathrm{P}: \mathrm{M}]$ that is, $a \alpha m \in \mathrm{P}$ or $\mathrm{b} \beta m^{\prime} \in \mathrm{P}$, which is a contradiction.

$(\Longleftarrow)$ Let $s \in \mathrm{S}$ and $x \in \mathrm{M}$ such that $\mathrm{s} \Gamma \mathrm{S} \Gamma x$ $\subseteq \mathrm{P}$. Suppose that $x \notin \mathrm{P}$. Let $m \in \mathrm{M}$. Since $\mathrm{M}$ is multiplication, then $\mathrm{S} \Gamma m=\mathrm{A} \Gamma \mathrm{M}$ and $\mathrm{S} \Gamma(s \alpha x)=\mathrm{B} \Gamma \mathrm{M}$ for some $\Gamma$-ideals $\mathrm{A}, \mathrm{B}$ of $\mathrm{S}$. Now, $\mathrm{S} \Gamma(s \alpha x) * \mathrm{~S} \Gamma m=(\mathrm{B} \Gamma \mathrm{A}) \Gamma \mathrm{M} \subseteq \mathrm{B} \Gamma \mathrm{M}=$ $\mathrm{S} \Gamma(s \alpha x) \subseteq s \Gamma \mathrm{S} \Gamma x \subseteq \mathrm{P}$. By hypothesis, we have $\mathrm{S} \Gamma(s \alpha x) \subseteq \mathrm{P}$ or $\mathrm{S} \Gamma m \subseteq \mathrm{P}$, but $x \notin \mathrm{P}$ so $s \Gamma \mathrm{M} \subseteq \mathrm{P}$. Hence, $\mathrm{P}$ is prime.

Let $\mathrm{M}$ be a multiplication $\mathrm{S}_{\Gamma}$-act and $m, m^{\prime}$ $\in \mathrm{M}$. Then $\mathrm{S} \Gamma m=\mathrm{A} \Gamma \mathrm{M}$ and $\mathrm{S} \Gamma m^{\prime}=\mathrm{B} \Gamma \mathrm{M}$ for some $\Gamma$-ideals A, B of S. So $m * m^{\prime}$ means the product of $\mathrm{S} \Gamma m$ and $\mathrm{S} \Gamma m^{\prime}$, which is equal to (АГВ)ГМ. As consequence of Theorem(2.7), we give the following Corollary:

\subsection{Corollary.}

Let $\mathrm{S}$ be $\Gamma$-monoid and $\mathrm{P}$ be a proper $\mathrm{S}_{\Gamma}$ - subact of a multiplication $\mathrm{S}_{\Gamma}$-act $\mathrm{M}$. Then $\mathrm{P}$ is prime if and only if $m * m^{\prime} \in \mathrm{P}$ then either $m \in \mathrm{P}$ or $m^{\prime} \in \mathrm{P}$ for each $m, m^{\prime} \in$ M.

\subsection{Definition.}

Let $\mathrm{N}$ be a $\mathrm{S}_{\Gamma}$-subact of $\mathrm{S}_{\Gamma}$-act $\mathrm{M}$. Then the radical of $\mathrm{N}$ is the intersection of all prime $\mathrm{S}_{\Gamma}$-subacts of $\mathrm{M}$ containing $\mathrm{N}$ and denoted by $\operatorname{rad}_{M}(\mathrm{~N})$. If $\mathrm{N}$ is not contained in any prime $\mathrm{S}_{\Gamma}$-subact of $\mathrm{M}$, then $\operatorname{rad}_{M}(\mathrm{~N})=\mathrm{M}$.

\subsection{Proposition.}

Let $\mathrm{S}$ be a commutative $\Gamma$-monoid and $\mathrm{N}$ be a proper $\mathrm{S}_{\Gamma}$-subact of a faithful multiplication $\quad \mathrm{S}_{\Gamma}$-act $\quad \mathrm{M}$. Then $\operatorname{rad}_{M}(\mathrm{~N})=\sqrt{[\mathrm{N}: \mathrm{M}]} \Gamma \mathrm{M}$.

Proof: Let $\mathcal{F}=\{\mathrm{P}: \mathrm{P}$ is prime $\Gamma$ - ideal of $\mathrm{S}$ such that $[\mathrm{N}: \mathrm{M}] \subseteq \mathrm{P}\}$. Let $\mathrm{B}=\sqrt{[\mathrm{N}: \mathrm{M}]}$ then $\mathrm{B}=\bigcap_{P \in \mathcal{F}} \mathrm{P}$ and hence, $\mathrm{B} \Gamma \mathrm{M}=\bigcap_{P \in \mathcal{F}}(\mathrm{P} \Gamma \mathrm{M})$. Let $\mathrm{P} \in \mathcal{F}$. If $\mathrm{M}=\mathrm{P} \Gamma \mathrm{M}$ then $\operatorname{rad}_{M}(\mathrm{~N}) \subseteq$ $\mathrm{P} \Gamma \mathrm{M}$. If $\mathrm{M} \neq \mathrm{P} \Gamma \mathrm{M}$ then $\mathrm{N}=[\mathrm{N}: \mathrm{M}] \Gamma \mathrm{M} \subseteq \mathrm{P} \Gamma \mathrm{M}$ by Proposition (2.4), РГM is prime $\mathrm{S}_{\Gamma}$-subact of $\mathrm{M}$. Thus $\operatorname{rad}_{M}(\mathrm{~N}) \subseteq \mathrm{P} \Gamma \mathrm{M}$. Therefore, $\operatorname{rad}_{M}(\mathrm{~N}) \subseteq \mathrm{B} \Gamma \mathrm{M}$. Conversely, let $\mathrm{K}$ be a prime $\mathrm{S}_{\Gamma}$-subact of $\mathrm{M}$ containing $\mathrm{N}$. Then by Proposition (2.4), there exists a prime $\Gamma$-ideal $\mathrm{P}$ of $\mathrm{S}$, such that $\mathrm{K}=\mathrm{P} \Gamma \mathrm{M}$ and Since $[\mathrm{N}: M] \Gamma \mathrm{M}=\mathrm{N} \subseteq \mathrm{K}=\mathrm{P} \Gamma \mathrm{M}$ then $[\mathrm{N}: \mathrm{M}] \subseteq$ $\mathrm{P}$, and hence $\sqrt{[\mathrm{N}: \mathrm{M}]} \subseteq \mathrm{P}$. So, $\sqrt{[\mathrm{N}: \mathrm{M}]} \Gamma \mathrm{M} \subseteq$ $\mathrm{P} \Gamma \mathrm{M}=\mathrm{K}$. Thus, $\sqrt{[\mathrm{N}: \mathrm{M}]} \Gamma \mathrm{M} \subseteq \operatorname{rad}_{M}(\mathrm{~N})$.

Now, we give the concept of completely globally idempotent as follows:

\subsection{Definition.}

A $\Gamma$-semigroup $\mathrm{S}$, is called completely globally idempotent if every $\Gamma$-ideal of $S$, is gl-idempotent.

\subsection{Example.}

Let $S=\Gamma=\{i, 0,-i\}$. Then $S$ is $\Gamma$-semigroup under the multiplication over complex numbers. Here, $\mathrm{A}_{1}=\{0\}$ and $\mathrm{A}_{2}=\mathrm{S}$ are the only $\Gamma$-ideals of $S$. It's clear that $A_{1}$ and $A_{2}$ are gl-idempotent. 


\section{Topological gamma acts}

In this section, we introduce the concept of a topological gamma act and its basic properties discussed. In what follows, $\mathrm{S}$ will denote a $\Gamma$-semigroup with zero, and all $\mathrm{S}_{\Gamma}$-acts contain the zero element.

\subsection{Definition.}

Let $\mathrm{M}$ be a $\mathrm{S}_{\Gamma}$-act. The gamma spectrum ( $\Gamma$-spectrum for short) of $M$ is the collection of prime $\mathrm{S}_{\Gamma}$-subacts of $\mathrm{M}$ and denoted by $\operatorname{Spec}_{\Gamma}(\mathrm{M})$. When $\mathrm{S}$ is an $\mathrm{S}_{\Gamma}$-act, then $\operatorname{Spec}_{\Gamma}(\mathrm{S})$ is the set of all prime $\Gamma$-ideals of $\mathrm{S}$.

\subsection{Definition.}

Let $\mathrm{N}$ be a $\mathrm{S}_{\Gamma}$-subact of $\mathrm{S}_{\Gamma}$-act $\mathrm{M}$. We define $V_{\Gamma}(\mathrm{N})$ to be the set of all prime $\mathrm{S}_{\Gamma}$-subacts of $\mathrm{M}$ containing $\mathrm{N}$, i.e $V_{\Gamma}(\mathrm{N})=\{\mathrm{P}$ $\left.\in \operatorname{Spec}_{\Gamma}(\mathrm{M}): \mathrm{N} \subseteq \mathrm{P}\right\}$. Note that, $V_{\Gamma}(\mathrm{M})$ is empty set and $V_{\Gamma}(\theta)$ is $\operatorname{Spec}_{\Gamma}(\mathrm{M})$.

It's easy to see that for $\mathrm{S}_{\Gamma}$-subacts $\mathrm{N}_{1}$ and $\mathrm{N}_{2}$ of $\mathrm{M}$ we have:

i. If $\mathrm{N}_{1} \subseteq \mathrm{N}_{2}$, then $V_{\Gamma}\left(\mathrm{N}_{2}\right) \subseteq V_{\Gamma}\left(\mathrm{N}_{1}\right)$.

ii. If $V_{\Gamma}(\mathrm{N})=\{\mathrm{N}\}$, then $\mathrm{N}$ is a prime. The converse is true if $\mathrm{N}$ is the unique prime $\mathrm{S}_{\Gamma}$-subact of $\mathrm{M}$.

iii. $V_{\Gamma}\left(\mathrm{N}_{1}\right) \cup V_{\Gamma}\left(\mathrm{N}_{2}\right) \subseteq V_{\Gamma}\left(\mathrm{N}_{1} \cap \mathrm{N}_{2}\right)$.

\subsection{Proposition.}

Let $\mathrm{S}$ be a $\Gamma$-monoid and $\mathrm{M}$ be a $\mathrm{S}_{\Gamma}$-act. Then for the $\mathrm{S}_{\Gamma}$-subacts $\mathrm{N}, \mathrm{N}_{1}$ and $\mathrm{N}_{2}$ of $\mathrm{M}$, the following conditions hold:

i. If $\mathrm{M}$ is a multiplication then, $V_{\Gamma}\left(\mathrm{N}_{1}\right) \mathrm{U}$ $V_{\Gamma}\left(\mathrm{N}_{2}\right)=V_{\Gamma}\left(\mathrm{N}_{1} * \mathrm{~N}_{2}\right)=V_{\Gamma}\left(\mathrm{N}_{1} \cap \mathrm{N}_{2}\right)$.

ii. $V_{\Gamma}\left(\operatorname{rad}_{\Gamma}(\mathrm{N})\right)=V_{\Gamma}(\mathrm{N})$.

iii. If $V_{\Gamma}\left(\mathrm{N}_{1}\right) \subseteq V_{\Gamma}\left(\mathrm{N}_{2}\right)$, then $\mathrm{N}_{2} \subseteq \operatorname{rad}_{\Gamma}\left(\mathrm{N}_{1}\right)$. iv. $V_{\Gamma}\left(\mathrm{N}_{1}\right)=V_{\Gamma}\left(\mathrm{N}_{2}\right)$ if and only if $\operatorname{rad}_{\Gamma}\left(\mathrm{N}_{1}\right)$ $=\operatorname{rad}_{\Gamma}\left(\mathrm{N}_{2}\right)$.

v. $\mathrm{N}_{1}=\mathrm{N}_{2}$ for any $\mathrm{S}_{\Gamma}$-subacts $\mathrm{N}_{1}, \mathrm{~N}_{2}$ of $\mathrm{M}$ whenever $V_{\Gamma}\left(\mathrm{N}_{1}\right)=V_{\Gamma}\left(\mathrm{N}_{2}\right)$ is equivalent to every proper $\mathrm{S}_{\Gamma}$-subact $\mathrm{N}$ is the intersection of primes.

vi. If $\left\{\mathrm{N}_{i}: i \in \mathrm{I}\right\}$ is a nonempty collection of $\mathrm{S}_{\Gamma^{-}}$ subacts of $\mathrm{M}$, then $\bigcap_{i \in I} V_{\Gamma}\left(\mathrm{N}_{i}\right)=V_{\Gamma}\left(\mathrm{U}_{i \in I} \mathrm{~N}_{i}\right)$.

Proof:(i) Let $\mathrm{P} \in V_{\Gamma}\left(\mathrm{N}_{1}\right) \cup V_{\Gamma}\left(\mathrm{N}_{2}\right)$. Then $\mathrm{P} \in$ $V_{\Gamma}\left(\mathrm{N}_{1}\right)$ or $\mathrm{P} \in V_{\Gamma}\left(\mathrm{N}_{2}\right)$ and hence $\mathrm{N}_{1} \subseteq \mathrm{P}$ or $\mathrm{N}_{2} \subseteq \mathrm{P}$. Since $\mathrm{N}_{1} * \mathrm{~N}_{2} \subseteq \mathrm{N}_{1}$ and $\mathrm{N}_{1} * \mathrm{~N}_{2} \subseteq \mathrm{N}_{2}$ thus $\mathrm{P} \in V_{\Gamma}\left(\mathrm{N}_{1} * \mathrm{~N}_{2}\right)$. Conversely, let $\mathrm{P}^{\prime} \in$ $V_{\Gamma}\left(\mathrm{N}_{1} * \mathrm{~N}_{2}\right)$ then $\mathrm{N}_{1} * \mathrm{~N}_{2} \subseteq \mathrm{P}^{\prime}$. By Theorem (2.7), $\mathrm{N}_{1} \subseteq \mathrm{P}^{\prime}$ or $\mathrm{N}_{2} \subseteq \mathrm{P}^{\prime}$ that is, $\mathrm{P}^{\prime} \in V_{\Gamma}\left(\mathrm{N}_{1}\right) \cup V_{\Gamma}\left(\mathrm{N}_{2}\right)$. For the other part let $Q \in V_{\Gamma}\left(\mathrm{N}_{1} * \mathrm{~N}_{2}\right)$ then $\mathrm{N}_{1} * \mathrm{~N}_{2} \subseteq Q$. Thus $\mathrm{N}_{1} \subseteq Q$ or $\mathrm{N}_{2} \subseteq Q$ which implies that $Q \in$ $V_{\Gamma}\left(\mathrm{N}_{1} \cap \mathrm{N}_{2}\right)$. The other direction is clear.

(ii) For $\mathrm{P} \in V_{\Gamma}(\mathrm{N})$ we have $\mathrm{N} \subseteq \mathrm{P}$ and hence $\operatorname{rad}_{\Gamma}(\mathrm{N}) \subseteq \mathrm{P}$. So $\mathrm{P} \in V_{\Gamma}\left(\operatorname{rad}_{\Gamma}(N)\right)$. Conversely $\mathrm{P}^{\prime} \in V_{\Gamma}\left(\operatorname{rad}_{\Gamma}(\mathrm{N})\right)$ then $\operatorname{rad}_{\Gamma}(\mathrm{N}) \subseteq \mathrm{P}^{\prime}$. Since $\mathrm{N} \subseteq \operatorname{rad}_{\Gamma}(\mathrm{N})$. Thus, $\mathrm{P}^{\prime} \in V_{\Gamma}(\mathrm{N})$. Therefore, $V_{\Gamma}\left(\operatorname{rad}_{\Gamma}(\mathrm{N})\right)=V_{\Gamma}(\mathrm{N})$.

(iii) By hypothesis, $\mathrm{N}_{2} \subseteq \mathrm{P}$ for every $\mathrm{P} \in$ $V_{\Gamma}\left(\mathrm{N}_{1}\right)$. Thus $\mathrm{N}_{2} \subseteq \bigcap_{P \in V_{\Gamma}\left(\mathrm{N}_{1}\right)} \mathrm{P}$ and hence $\mathrm{N}_{2} \subseteq \operatorname{rad}_{\Gamma}\left(\mathrm{N}_{1}\right)$.

(iv) Clearly, $\operatorname{rad}_{\Gamma}\left(\mathrm{N}_{1}\right)=\bigcap_{N_{1} \subseteq P} \mathrm{P}=\bigcap_{P \in V_{\Gamma}\left(\mathrm{N}_{1}\right)} \mathrm{P}$ $=\bigcap_{P \in V_{\Gamma}\left(\mathrm{N}_{2}\right)} \mathrm{P}=\operatorname{rad}_{\Gamma}\left(\mathrm{N}_{2}\right)$. Conversely, by (ii) $V_{\Gamma}\left(\mathrm{N}_{1}\right)=V_{\Gamma}\left(\operatorname{rad}_{\Gamma}\left(\mathrm{N}_{1}\right)=V_{\Gamma}\left(\operatorname{rad}_{\Gamma}\left(\mathrm{N}_{2}\right)=V_{\Gamma}\left(\mathrm{N}_{2}\right)\right.\right.$.

$(\mathrm{v})(\Longrightarrow)$ Suppose $\mathrm{N}_{1}$ is a proper $\mathrm{S}_{\Gamma}$-subact of M. If $V_{\Gamma}\left(\mathrm{N}_{1}\right)=\varnothing$, then $V_{\Gamma}\left(\mathrm{N}_{1}\right)=V_{\Gamma}(\mathrm{M})$. By hypothesis $\mathrm{N}_{1}=\mathrm{M}$, a contradiction. Thus $V_{\Gamma}\left(\mathrm{N}_{1}\right)$ $\neq \emptyset$, we obtain $\mathrm{N}_{2}=\bigcap_{P \in V_{\Gamma}\left(\mathrm{N}_{1}\right)} \mathrm{P}=\operatorname{rad}_{\Gamma}\left(\mathrm{N}_{1}\right)$. Then, $\quad V_{\Gamma}\left(\mathrm{N}_{2}\right)=V_{\Gamma}\left(\operatorname{rad}_{\Gamma}\left(\mathrm{N}_{1}\right)=V_{\Gamma}\left(\mathrm{N}_{1}\right)\right.$, since $\mathrm{N}_{1}=\mathrm{N}_{2}$. Hence, $\mathrm{N}_{1}$ is an intersection of prime $\mathrm{S}_{\Gamma}$-subacts.

$(\Longleftarrow)$ Assume that $V_{\Gamma}\left(\mathrm{N}_{1}\right)=V_{\Gamma}\left(\mathrm{N}_{2}\right)$. It's clear by hypothesis every $\mathrm{S}_{\Gamma}$-subact $\mathrm{N}$ of $\mathrm{M}$ is an intersection of prime $\mathrm{S}_{\Gamma}$-subacts if and only if $\mathrm{N}=\bigcap_{P \in V_{\Gamma}(\mathrm{N})} \mathrm{P}$. Now, $\mathrm{N}_{1}=\bigcap_{P \in V_{\Gamma}\left(\mathrm{N}_{1}\right)} \mathrm{P}$ and $\mathrm{N}_{2}=\bigcap_{P \in V_{\Gamma}\left(\mathrm{N}_{2}\right)} P$. It follows that $\mathrm{N}_{1}=\mathrm{N}_{2}$.

(vi) Let $\mathrm{P} \in \bigcap_{i \in I} V_{\Gamma}\left(\mathrm{N}_{i}\right)$. Then $\mathrm{P} \in V_{\Gamma}\left(\mathrm{N}_{i}\right)$ and hence $\mathrm{N}_{i} \subseteq \mathrm{P}$ for all $i \in I$. Thus, $\bigcup_{i \in I} N_{i} \subseteq \mathrm{P}$. So, 
$\mathrm{P} \in V_{\Gamma}\left(\mathrm{U}_{i \in I} N_{i}\right)$. Conversely, let $\mathrm{Q} \in V_{\Gamma}\left(\mathrm{U}_{i \in I} N_{i}\right)$. Then, $\mathrm{U}_{i \in I} N_{i} \subseteq \mathrm{Q}$. We conclude that $\mathrm{N}_{i} \subseteq \mathrm{Q}$ and hence $\mathrm{Q} \in V_{\Gamma}\left(\mathrm{N}_{i}\right)$ for every $i \in \mathrm{I}$. Thus, $\mathrm{Q} \in$ $\bigcap_{i \in I} V_{\Gamma}\left(\mathrm{N}_{i}\right)$. Hence, $\bigcap_{i \in I} V_{\Gamma}\left(\mathrm{N}_{i}\right)=V_{\Gamma}\left(\bigcup_{i \in I} \mathrm{~N}_{i}\right)$.

Now, we introduce the definition of topological gamma act as follows:

\subsection{Definition.}

Let $\mathrm{M}$ be a $\mathrm{S}_{\Gamma}$-act, and $\tau(\mathrm{M})=\left\{V_{\Gamma}(\mathrm{N}): \mathrm{N}\right.$ is $\mathrm{S}_{\Gamma}$-subact of $\mathrm{M}$ \}. If $\tau(\mathrm{M})$ is closed under finite unions, then the family $\tau(\mathrm{M})$ satisfies the axioms for the closed subsets of a topological space. Thus, $\tau(\mathrm{M})$ is a topology on $\operatorname{Spec}_{\Gamma}(\mathrm{M})$ called the gamma act topology.

\subsection{Examples.}

1. Let $\mathrm{S}=\mathrm{M}=\{w, x, y, z\}$ and $\Gamma$ any nonempty set. Then, $\mathrm{M}$ is an $\mathrm{S}_{\Gamma}$-act under the multiplication mapping: $\mathrm{S} \times \Gamma \times \mathrm{M}$ $\rightarrow \mathrm{M}$ defined by $\mathrm{a} \alpha \mathrm{b}=\mathrm{ab}$, which given in the following table:

\begin{tabular}{|c|c|c|c|c|}
\hline$\cdot$ & $w$ & $x$ & $y$ & $z$ \\
\hline$w$ & $w$ & $w$ & $w$ & $w$ \\
\hline$x$ & $w$ & $w$ & $w$ & $x$ \\
\hline$y$ & $w$ & $w$ & $w$ & $w$ \\
\hline$z$ & $w$ & $w$ & $y$ & $z$ \\
\hline
\end{tabular}

Here $\{w\},\{w, x\},\{w, y\}$ and $\{w, x, y\}$ are the $\mathrm{S}_{\Gamma^{-}}$subacts of M. But, $\{w, x, y\}$ is the only prime $\mathrm{S}_{\Gamma}$-subact of M. So, $\operatorname{Spec}_{\Gamma}(\mathrm{M})=\{\{w, x, y\}\}$, $V_{\Gamma}(\{w\})=V_{\Gamma}(\{w, x\})=V_{\Gamma}(\{w, y\})=\operatorname{Spec}_{\Gamma}(\mathrm{M})$ and $V_{\Gamma}(\mathrm{M})=\emptyset$. So, $\tau(\mathrm{M})=\left\{\varnothing, \operatorname{Spec}_{\Gamma}(\mathrm{M})\right\}$.In this case $\tau(\mathrm{M})$ is the indiscrete topological $\mathrm{S}_{\Gamma}$-act.

2. Let $\mathrm{S}=\mathbb{Z}_{6}, \Gamma=\{\overline{1}, \overline{3}\}$, and $\mathrm{M}=\mathrm{S}$. Clearly, $\mathrm{M}$ is an $\mathrm{S}_{\Gamma}$-act under multiplication mod 6 . The $\mathrm{S}_{\Gamma}$-subacts of $\mathrm{M}$ are $\mathrm{N}_{1}=\{\overline{0}\}, \mathrm{N}_{2}=\{\overline{0}, \overline{2}$, $\overline{4}\}, \mathrm{N}_{3}=\{\overline{0}, \overline{3}\}$, and $\mathrm{N}_{4}=\{\overline{0}, \overline{2}, \overline{3}, \overline{4}\}$. It's clear that $\mathrm{N}_{2}, \mathrm{~N}_{3}, \mathrm{~N}_{4}$ are the only prime $\mathrm{S}_{\Gamma}$-subacts of $\mathrm{M}$.
Thus, $\operatorname{Spec}_{\Gamma}(\mathrm{M})=\left\{\mathrm{N}_{2}, \mathrm{~N}_{3}, \mathrm{~N}_{4}\right\}$, $V_{\Gamma}\left(\mathrm{N}_{1}\right)=\operatorname{Spec}_{\Gamma}(\mathrm{M}), V_{\Gamma}(\mathrm{M})=\emptyset, V_{\Gamma}\left(\mathrm{N}_{2}\right)=\left\{\mathrm{N}_{2} \mathrm{~N}_{4}\right\}$, $V_{\Gamma}\left(\mathrm{N}_{3}\right)=\left\{\mathrm{N}_{3}, \mathrm{~N}_{4}\right\}$ and $V_{\Gamma}\left(\mathrm{N}_{4}\right)=\left\{\mathrm{N}_{4}\right\}$. Hence, $\tau(\mathrm{M})=\left\{\varnothing, \operatorname{Spec}_{\Gamma}(\mathrm{M}),\left\{\mathrm{N}_{2}, \mathrm{~N}_{4}\right\},\left\{\mathrm{N}_{3}, \mathrm{~N}_{4}\right\},\left\{\mathrm{N}_{4}\right\}\right\}$.

3. Let $\mathrm{S}=\mathrm{M}=\{a, b, c, d, e, f\}$ and $\Gamma$ be a nonempty set. Then $\mathrm{M}$ is an $\mathrm{S}_{\Gamma}$-act under the mapping: $\mathrm{S} \times \Gamma \times \mathrm{M} \rightarrow \mathrm{M}$, which defined by:

$$
x \alpha y=\left\{\begin{array}{l}
a \text { if } x=f, y=a \\
b \text { if } x=f, y=b \\
c \text { if } x=f, y=c \\
f \text { if } x=f=y \\
e \text { if } x \in \mathrm{M}, y=b \text { or } y=e \\
d \text { otherwise. }
\end{array}\right.
$$

Here, the $\mathrm{S}_{\Gamma}$-subacts of $\mathrm{M}$ are: $\mathrm{N}_{1}=\{a, d, e, f\}$, $\mathrm{N}_{2}=\{b, d, e, f\}, \mathrm{N}_{3}=\{c, d, e, f\}, \mathrm{N}_{4}=\{b, c, d$, $e, f\}, \mathrm{N}_{5}=\{a, c, d, e, f\}, \mathrm{N}_{6}=\{a, b, d, e, f\}$ and $\mathrm{N}_{7}=\mathrm{M}$. Then it can be easily verified that, $V_{\Gamma}\left(\mathrm{N}_{1}\right)=\left\{N_{1}, N_{6}, N_{5}\right\}, V_{\Gamma}\left(\mathrm{N}_{2}\right)=\left\{\mathrm{N}_{2}, \mathrm{~N}_{6}\right.$, $\left.\mathrm{N}_{4}\right\}, V_{\Gamma}\left(\mathrm{N}_{3}\right)=\left\{\mathrm{N}_{3}, \mathrm{~N}_{4}, \mathrm{~N}_{5}\right\}, V_{\Gamma}\left(\mathrm{N}_{4}\right)=\left\{\mathrm{N}_{4}\right\}$, $V_{\Gamma}\left(\mathrm{N}_{5}\right)=\left\{\mathrm{N}_{5}\right\}$ and $V_{\Gamma}\left(\mathrm{N}_{6}\right)=\left\{\mathrm{N}_{6}\right\}$.

But $V_{\Gamma}\left(\mathrm{N}_{5}\right) \cup V_{\Gamma}\left(\mathrm{N}_{6}\right)=\left\{\mathrm{N}_{6}, \mathrm{~N}_{5}\right\} \neq V_{\Gamma}\left(\mathrm{N}_{i}\right)$ for all $i=1,2,3,4,5,6$ and $V_{\Gamma}\left(\mathrm{N}_{5}\right) \cup V_{\Gamma}\left(\mathrm{N}_{6}\right) \neq V_{\Gamma}\left(\mathrm{N}_{5} \cap \mathrm{N}_{6}\right)$.

Now, we identify some cases for which $\tau(\mathrm{M})$ is a topological gamma act. Before this, we need the following definitions.

\subsection{Definition.}

An $\mathrm{S}_{\Gamma}$-subact $\mathrm{N}$ of $\mathrm{S}_{\Gamma-\text { act }} \mathrm{M}$ is called semiprime if $\mathrm{N}$ is an intersection of prime $\mathrm{S}_{\Gamma}$-subacts of $\mathrm{M}$.

\subsection{Definition.}

A prime $\mathrm{S}_{\Gamma^{-}}$subact $\mathrm{N}$ of $\mathrm{S}_{\Gamma^{-}}$act $\mathrm{M}$ is said to be extraordinary if whenever $\mathrm{K}$ and $\mathrm{L}$ are semiprime $\mathrm{S}_{\Gamma}$ - subacts of $\mathrm{M}$ with $\mathrm{K} \cap \mathrm{L} \subseteq \mathrm{N}$ then $\mathrm{K} \subseteq \mathrm{N}$ or $\mathrm{L} \subseteq \mathrm{N}$.

\subsection{Example.}

Let $S=\Gamma=\mathbb{Z}$ and $M=6 \mathbb{Z}$. Then $M$ is a $S_{\Gamma^{-}}$ act under the usual multiplication of integer numbers. 
It is clear that $\operatorname{Spec}_{\Gamma}(\mathrm{M})=\{(6 p) \Gamma S: p \in \mathbb{P}$ where $\mathbb{P}$ is the set of prime numbers $\}$. Thus, any semiprime $\mathrm{S}_{\Gamma}$-subact $\mathrm{N}$ of $\mathrm{M}$ has a form $\mathrm{N}=\bigcap_{i \in \mathrm{I}}\left(6 p_{i}\right) \Gamma \mathrm{S}$, for some $p_{i} \in \mathbb{P}$. Also, the prime $\mathrm{S}_{\Gamma}$-subact $\mathrm{P}=(12) \Gamma \mathrm{S}$ of $\mathrm{M}$ is extraordinary. Let $\mathrm{K}$ and $\mathrm{L}$ be semiprime $\mathrm{S}_{\Gamma}$-subacts of $\mathrm{M}$, such that $\mathrm{K}=\mathrm{\bigcap}(6 p) \Gamma \mathrm{S}$ and $\mathrm{L}=\bigcap(6 q) \Gamma \mathrm{S}$, where the intersection runs among some $p, q$ in $\mathbb{P}$. Thus, $\mathrm{K}=(6 m) \Gamma \mathrm{S}$ and $\mathrm{L}=(6 n) \Gamma \mathrm{S}$ where $m, n \in \mathbb{Z}$. Hence, $\mathrm{K} \cap \mathrm{L}$ $=(6 n m) \Gamma S \subseteq \mathrm{P}=6(2) \Gamma S$.So, we have 2 divides $n m$ then 2 divides $n$ or 2 divides $m$. This, implies that $\mathrm{K} \subseteq \mathrm{P}$ or $\mathrm{L} \subseteq \mathrm{P}$.

\subsection{Theorem.}

For a $\mathrm{S}_{\Gamma}$-act $\mathrm{M}$. The following conditions are equivalent:

i. $\mathrm{M}$ is a Top $\mathrm{S}_{\Gamma}$-act.

ii. Every prime $\mathrm{S}_{\Gamma}$-subact of $\mathrm{M}$ is extraordinary iii. $V_{\Gamma}(\mathrm{N}) \cup V_{\Gamma}(\mathrm{K})=V_{\Gamma}(\mathrm{N} \cap \mathrm{K})$ for all semiprime $\mathrm{S}_{\Gamma}$-subacts $\mathrm{N}$ and $\mathrm{K}$ of $\mathrm{M}$.

Proof:(i) $\Longrightarrow$ (ii) Let $\mathrm{K}$ be a prime $\mathrm{S}_{\Gamma}$-subact of $\mathrm{M}$ and $\mathrm{N}, \mathrm{L}$ be semiprime $\mathrm{S}_{\Gamma}$-subacts of $M$ such that $\mathrm{N} \cap \mathrm{L} \subseteq \mathrm{K}$. By assumption, there is an $\mathrm{S}_{\Gamma}$-subact $\mathrm{T}$ of $\mathrm{M}$ such that $V_{\Gamma}(\mathrm{N}) \cup V_{\Gamma}(\mathrm{L})=V_{\Gamma}(\mathrm{T})$. Since $\mathrm{N}$ is semiprime, then there exists a collection of prime $\mathrm{S}_{\Gamma}-$ subacts $K_{i},(i \in \mathrm{I})$ such that, $\mathrm{N}=\bigcap_{i \in I} K_{i}$. So, for all $i \in \mathrm{I}, K_{i} \in V_{\Gamma}(\mathrm{N}) \subseteq V_{\Gamma}(\mathrm{T})$, and hence $\mathrm{T} \subseteq K_{i}$ for all $i \in I$. Thus, $\mathrm{T} \subseteq \bigcap_{i \in I} K_{i}=\mathrm{N}$. Similarly $\mathrm{T} \subseteq \mathrm{L}$. So $\mathrm{T} \subseteq \mathrm{N} \cap \mathrm{L}$. Now, $V_{\Gamma}(\mathrm{N}) \cup V_{\Gamma}(\mathrm{L}) \subseteq V_{\Gamma}(\mathrm{N} \cap \mathrm{L}) \subseteq V_{\Gamma}(\mathrm{T})=V_{\Gamma}(\mathrm{N}) \cup V_{\Gamma}(\mathrm{L})$. We conclude that $V_{\Gamma}(\mathrm{N}) \cup V_{\Gamma}(\mathrm{L})=V_{\Gamma}(\mathrm{N} \cap \mathrm{L})$. But, $\mathrm{K} \in V_{\Gamma}(\mathrm{N} \cap \mathrm{L})$. Thus, $\mathrm{K} \in V_{\Gamma}(\mathrm{N})$ or $\mathrm{K} \in$ $V_{\Gamma}(\mathrm{L})$. Hence, $\mathrm{N} \subseteq \mathrm{K}$ or $\mathrm{N} \subseteq \mathrm{L}$. Therefore, $\mathrm{K}$ is extraordinary.

(ii) $\Rightarrow$ (iii) Suppose that $N$ and $K$ semiprime $\mathrm{S}_{\Gamma}$-subacts of $\mathrm{M}$. It's clear that $V_{\Gamma}(N) \mathrm{U}$ $V_{\Gamma}(K) \subseteq V_{\Gamma}(N \cap K)$. Let $\mathrm{L} \in V_{\Gamma}(N \cap K)$. Then, $N \cap K \subseteq$ L. Since L is prime then by (ii), $N \subseteq \mathrm{L}$ or $K \subseteq \mathrm{L}$, i.e $\mathrm{L} \in V_{\Gamma}(N)$ or $\mathrm{L} \in V_{\Gamma}(K)$. This shows that $V_{\Gamma}(N \cap K) \subseteq V_{\Gamma}(\mathrm{N}) \cup V_{\Gamma}(\mathrm{K})$. Hence, $V_{\Gamma}(\mathrm{N}) \cup V_{\Gamma}(\mathrm{K})=V_{\Gamma}(\mathrm{N} \cap \mathrm{K})$. (iii) $\Longrightarrow$ (i) Let $K_{1}$ and $K_{2}$ be any $\mathrm{S}_{\Gamma}$-subacts of M. If $V_{\Gamma}\left(K_{1}\right)$ is empty, then $V_{\Gamma}\left(K_{1}\right) \mathrm{U}$ $V_{\Gamma}\left(K_{2}\right)=V_{\Gamma}\left(K_{2}\right)$. Assume that $V_{\Gamma}\left(K_{1}\right)$ and $V_{\Gamma}\left(K_{2}\right)$ are both nonempty. Then, $V_{\Gamma}\left(K_{1}\right)$ $\cup V_{\Gamma}\left(K_{2}\right)=V_{\Gamma}\left(\operatorname{rad}_{\Gamma}\left(K_{1}\right)\right) \cup V_{\Gamma}\left(\operatorname{rad}_{\Gamma}\left(K_{2}\right)\right)$ $=V_{\Gamma}\left(\operatorname{rad}_{\Gamma}\left(K_{1}\right) \cap \operatorname{rad}_{\Gamma}\left(K_{2}\right)\right)$. Thus, $\mathrm{M}$ is a Top $\mathrm{S}_{\Gamma}$-act.

If $\left\{\mathrm{A}_{i}, 1 \leq i \leq n\right\}$ is any nonempty family of $\Gamma$-ideals of $\Gamma$-semigroup $\mathrm{S}$, then , $\mathrm{A}_{1} \Gamma \mathrm{A}_{2} \Gamma$ $\ldots \Gamma A_{n} \subseteq A_{1} \cap A_{2} \cap \ldots \cap A_{n}$.

\subsection{Corollary.}

Let $\mathrm{M}$ be a $\mathrm{S}_{\Gamma}$-act with the property that for every prime $\mathrm{S}_{\Gamma}$-subact $\mathrm{N}$ of $\mathrm{M}$, $[\mathrm{K}: \mathrm{M}] \subseteq[\mathrm{N}: \mathrm{M}]$ implies that $\mathrm{K} \subseteq \mathrm{N}$ for each semiprime $\mathrm{S}_{\Gamma}$-subact $\mathrm{K}$ of $\mathrm{M}$. Then $\mathrm{M}$ is a Top $\mathrm{S}_{\Gamma}$-act.

Proof: Let $\mathrm{K}_{1}, \mathrm{~K}_{2}$ be a semiprime $\mathrm{S}_{\Gamma}$-subacts of $\mathrm{M}$ with $K_{1} \cap K_{2} \subseteq \mathrm{N}$. It follows that $\left[\mathrm{K}_{1}: \mathrm{M}\right] \cap\left[\mathrm{K}_{2}: \mathrm{M}\right]=\left[\mathrm{K}_{1} \cap \mathrm{K}_{2}: \mathrm{M}\right] \subseteq[\mathrm{N}: \mathrm{M}]$, since $[\mathrm{N}: \mathrm{M}]$ is a prime $\Gamma$-ideal of $\mathrm{S}$, then either $\left[\mathrm{K}_{1}: \mathrm{M}\right] \subseteq[\mathrm{N}: \mathrm{M}]$ or $\left[\mathrm{K}_{2}: \mathrm{M}\right] \subseteq[\mathrm{N}: \mathrm{M}]$. Now, by hypothesis, we have $\mathrm{K}_{1} \subseteq \mathrm{N}$ or $\mathrm{K}_{2} \subseteq \mathrm{N}$, that is, $\mathrm{N}$ is extraordinary. Hence, $\mathrm{M}$ is a Top $\mathrm{S}_{\Gamma}$-act by Theorem (3.9).

\subsection{Corollary.}

Any homomorphic image of a Top $\mathrm{S}_{\Gamma-\text {-act }}$ is a Top $\mathrm{S}_{\Gamma}$-act.

Proof: Consider the $\mathrm{S}_{\Gamma}$-epimorphism $\pi: \mathrm{M} \rightarrow$ $\mathrm{M} / \rho$, where $\rho$ a congruence on M. Let $\mathrm{N} / \rho_{N}$ be a prime $\mathrm{S}_{\Gamma}$-subact of $\mathrm{S}_{\Gamma}$-act $\mathrm{M} / \rho$, where $\mathrm{N}$ is a prime $\mathrm{S}_{\Gamma^{-}}$-subact of $\mathrm{M}$ (by Proposition (2.5)). Consequently, any semiprime $\mathrm{S}_{\Gamma^{-}}$ subact of $\mathrm{M} / \rho$ is of the form $\mathrm{K} / \rho_{K}$ for which $\mathrm{K}$ is semiprime $\mathrm{S}_{\Gamma}$-subact of $\mathrm{M}$. Let $K_{1} / \rho_{K_{1}}$ and $K_{2} / \rho_{K_{2}}$ be semiprime $\mathrm{S}_{\Gamma}$-subac of $\mathrm{M} / \rho$ such that $\left(K_{1} / \rho_{K_{1}} \cap K_{2} / \rho_{K_{2}}\right) \subseteq \mathrm{N} / \rho_{N}$. Then, $\pi^{-1}\left(K_{1} / \rho_{K_{1}} \cap K_{2} / \rho_{K_{2}}\right) \subseteq \pi^{-1}\left(\mathrm{~N} / \rho_{N}\right)$. So $\pi^{-1}\left(K_{1} / \rho_{K_{1}}\right) \cap \pi^{-1}\left(K_{2} / \rho_{K_{2}}\right) \subseteq \pi^{-1}\left(\mathrm{~N} / \rho_{N}\right)$. Thus, $\mathrm{K}_{1} \cap \mathrm{K}_{2} \subseteq \mathrm{N}$. It follows that $\mathrm{K}_{1} \subseteq \mathrm{N}$ or $K_{2} \subseteq \mathrm{N}$ and hence, $\pi\left(\mathrm{K}_{1}\right) \subseteq \pi(\mathrm{N})$ or 
$\pi\left(K_{2}\right) \subseteq \pi(\mathrm{N})$. Thus, $\mathrm{K}_{1} / \rho_{K_{1}} \subseteq \mathrm{N} / \rho_{N}$ or $K_{2} / \rho_{K_{2}} \subseteq \mathrm{N} / \rho_{N}$. Hence, $\mathrm{N} / \rho_{N}$ is extraordinary. So, by Theorem (3.9), $\mathrm{M} / \rho$ is Top $\mathrm{S}_{\Gamma}$-act. Now, let $\mathrm{P}$ be a prime $\Gamma$-ideal of $\Gamma$-semigroup $\mathrm{S}$ and $\mathrm{A}_{1}, \mathrm{~A}_{2}$ be a semiprime $\Gamma$-ideals of $\mathrm{S}$ with $A_{1} \cap A_{2} \subseteq P$. Since $A_{1} \Gamma A_{2} \subseteq A_{1} \cap A_{2} \subseteq$ $\mathrm{P}$, then $\mathrm{A}_{1} \subseteq \mathrm{P}$ or $\mathrm{A}_{2} \subseteq \mathrm{P}$ and hence $\mathrm{P}$ is extraordinary. Thus, by Theorem (3.9) any $\Gamma$-semigroup $\mathrm{S}$ is a Top $\mathrm{S}_{\Gamma}$-act .

Recall, if $\mathrm{M}$ and $\mathrm{N}$ are $\mathrm{S}_{\Gamma}$-acts, $f: \mathrm{M} \rightarrow \mathrm{N}$ $\mathrm{S}_{\Gamma}$-homomorphism, then $\mathrm{M} / \operatorname{ker}(f) \cong \operatorname{Im}(f)$. (Kamal, 2016)

Now, we study the relation between cyclic and topological gamma acts. For this reason, we give the following Proposition.

\subsection{Proposition.}

Let $\mathrm{M}$ be a $\mathrm{S}_{\Gamma}$-act. If $\mathrm{M}$ is cyclic, then $\mathrm{M} \cong \mathrm{S} / \ell_{\mathrm{S}}(m)$ for some $m \in \mathrm{M}$. Proof: Let $\mathrm{M}$ be a cyclic $\mathrm{S}_{\Gamma}$-act. Then, there exists $m \in \mathrm{M}$ such that $\mathrm{M}=\mathrm{S} \Gamma m$. Define, $f: S \rightarrow \mathrm{M}$ by $f(\mathrm{~s})=\mathrm{s} \alpha m$ for every $\mathrm{s} \in \mathrm{S}$ and $\alpha \in \Gamma$. Now, let $\mathrm{s}, \quad \mathrm{s}^{\prime} \in \mathrm{S}$ and $\beta \in \Gamma$, thus $f\left(\mathrm{~s} \beta \mathrm{s}^{\prime}\right)=\left(\mathrm{s} \beta \mathrm{s}^{\prime}\right) \alpha m=\mathrm{s} \beta\left(\mathrm{s}^{\prime} \alpha m\right)=\mathrm{s} \beta f\left(\mathrm{~s}^{\prime}\right)$ and hence $f$ is a $\mathrm{S}_{\Gamma}$-homomorphism. Also, let $m^{\prime} \in \mathrm{M}$, then $m^{\prime}=t \gamma m=f(t)$. Hence, $\mathrm{M} \cong \mathrm{S} / \operatorname{ker}(f)$.Since $\operatorname{ker}(f)=\{(s, t) \in \mathrm{S} \times \mathrm{S} \mid f(s)=f(t)\}=\{(s, t) \in \mathrm{S} \times \mathrm{S} \mid$ $s \alpha m=t \alpha m\}=\ell_{\mathrm{S}}(m)$. Thus, $\mathrm{M} \cong \mathrm{S} / \ell_{\mathrm{S}}(m)$.

\subsection{Corollary.}

Any cyclic $\mathrm{S}_{\Gamma}$-act is a Top $\mathrm{S}_{\Gamma-\text { act }}$.

Proof: It's clear by Corollary (3.11) and

Proposition (3.12).

But the converse of Corollary (3.13) may not be true, as we can see in the first part of example (3.5).

\subsection{Corollary.}

Let $\mathrm{S}$ be a $\Gamma$-semigroup and $\mathrm{T}$ be a $\Gamma$-sub-semigroup of $\mathrm{S}$. If $\mathrm{M}$ is a Top $\mathrm{T}_{\Gamma}$-act, then $\mathrm{M}$ is a Top $\mathrm{S}_{\Gamma}$-act.

Proof: Let $\mathrm{K}$ be a prime $\mathrm{S}_{\Gamma}$-subact of $\mathrm{M}$. Then $\mathrm{K}$ is a proper $\mathrm{T}_{\Gamma}$-subact of $\mathrm{M}$. If $t, s \in \mathrm{T}$, $m \in \mathrm{M}$ and $\alpha, \beta \in \Gamma$ satisfy $t \alpha s \beta m \in \mathrm{K}$ then $m \in \mathrm{K}$ or $t \Gamma \mathrm{M} \subseteq \mathrm{K}$. Thus $\mathrm{K}$ is a prime $\mathrm{T}_{\Gamma}$-subact of $\mathrm{M}$. Let $\mathrm{L}_{1}$ and $\mathrm{L}_{2}$ be semiprime $\mathrm{S}_{\Gamma}$-subacts of $\mathrm{M}$ with $\mathrm{L}_{1} \cap \mathrm{L}_{2} \subseteq \mathrm{K}$. By the same way above, we have $L_{1}$ and $L_{2}$ are semiprime $T_{\Gamma}$-subact of $M$. Since $M$ is a Top $\mathrm{T}_{\Gamma}$-act then, $\mathrm{L}_{1} \subseteq \mathrm{K}$ or $L_{2} \subseteq \mathrm{K}$. Thus, $\mathrm{K}$ is extraordinary. Hence, by Theorem (3.9), $\mathrm{M}$ is a Top $\mathrm{S}_{\Gamma}$-act.

\subsection{Proposition.}

Let $\mathrm{A}$ be a $\Gamma$-ideal of $\Gamma$ - monoid $\mathrm{S}$ and $\mathrm{N}$ be a $\mathrm{S}_{\Gamma}$-subact of $\mathrm{S}_{\Gamma}$-act $\mathrm{M}$. Then $V_{\Gamma}(\mathrm{N}) \cup V_{\Gamma}(\mathrm{A} \Gamma \mathrm{M})=V_{\Gamma}(\mathrm{A} \Gamma \mathrm{N})=V_{\Gamma}(\mathrm{N} \cap \mathrm{A} \Gamma \mathrm{M})$.

Proof: It's clear that, $V_{\Gamma}(\mathrm{N}) \cup V_{\Gamma}(\mathrm{A} \Gamma \mathrm{M}) \subseteq$ $V_{\Gamma}(\mathrm{N} \cap \mathrm{A} \Gamma \mathrm{M}) \subseteq V_{\Gamma}(\mathrm{A} \Gamma \mathrm{N})$. Let $\mathrm{P} \in V_{\Gamma}(\mathrm{A} \Gamma \mathrm{N})$. Then $\mathrm{A} \Gamma \mathrm{N} \subseteq \mathrm{P}$. This implies that $\mathrm{A} \Gamma 1 \Gamma \mathrm{N} \subseteq$ $\mathrm{P}$ and hence $\mathrm{A} \Gamma \mathrm{S} \Gamma \mathrm{N} \subseteq \mathrm{P}$. Since $\mathrm{P}$ is a prime, then $\mathrm{N} \subseteq \mathrm{P}$ or $\mathrm{A} \Gamma \mathrm{M} \subseteq \mathrm{P}$. So, $\mathrm{P} \in V_{\Gamma}(\mathrm{N})$ or $\mathrm{P} \in$ $V_{\Gamma}(\mathrm{A} \Gamma \mathrm{M}) . \quad$ Thus, $\quad \mathrm{P} \in V_{\Gamma}(\mathrm{N}) \cup V_{\Gamma}(\mathrm{A} \Gamma \mathrm{M})$. Therefore, $V_{\Gamma}(\mathrm{A} \Gamma \mathrm{M}) \subseteq V_{\Gamma}(\mathrm{N}) \cup V_{\Gamma}(\mathrm{A} \Gamma \mathrm{M})$.

\subsection{Corollary.}

Let $\mathrm{A}$ and $\mathrm{B}$ be a $\Gamma$-ideals of $\Gamma$-monoid $\mathrm{S}$ and $\mathrm{M}$ be a $\mathrm{S}_{\Gamma}$-act. Then $V_{\Gamma}(\mathrm{A} \Gamma \mathrm{M}) \cup V_{\Gamma}(\mathrm{B} \Gamma \mathrm{M})=V_{\Gamma}[(\mathrm{A} \Gamma \mathrm{B}) \Gamma \mathrm{M}]$.

Now, if $\left\{\mathrm{A}_{i}\right\}_{i \in I}$ is a collection of $\Gamma$-ideals of $\mathrm{S}$, then it's easy to show that, $\bigcap_{i \in I} V_{\Gamma}\left(\mathrm{A}_{i} \Gamma \mathrm{M}\right)$ $=V_{\Gamma}\left(\bigcup_{i \in I} \mathrm{~A}_{i} \Gamma \mathrm{M}\right)$. Thus, by using this fact with Corollary (3.16), we get the subset $\tau(\mathrm{A} \Gamma \mathrm{M})=\left\{V_{\Gamma}(\mathrm{A} \Gamma \mathrm{M})\right.$ : where $\mathrm{A}$ is $\Gamma$-ideal of $\mathrm{S}\}$ of $\tau(\mathrm{M})$ is a topological space, and if $\mathrm{M}$ is a Top $\mathrm{S}_{\Gamma}$-act, then $\tau(\mathrm{A} \Gamma \mathrm{M})$ is a subspace of $\tau(\mathrm{M})$. In particular, if $\mathrm{M}$ is a multiplication then $\mathrm{M}$ is a Top $\mathrm{S}_{\Gamma}$-act. Thus, we have the following result:

\subsection{Proposition.}

Ever multiplication $\mathrm{S}_{\Gamma}$-act is a Top $\mathrm{S}_{\Gamma}$-act.

3.18. Corollary.

If $\mathrm{S}$ is completely globally idempotent $\Gamma$-semigroup then any $\Gamma$-ideal of $S$ is a Top $\mathrm{S}_{\Gamma}$-act. 
Proof: Let $A$ and $B$ be $\Gamma$-ideals of $S$, such that $\mathrm{B} \subseteq \mathrm{A}$. Then $\mathrm{B}=\mathrm{B} \Gamma \mathrm{B} \subseteq \mathrm{B} \Gamma \mathrm{A} \subseteq \mathrm{B}$. Hence, $\mathrm{B}=\mathrm{B} \Gamma \mathrm{A}$. Thus, $\mathrm{A}$ is a multiplication. By Proposition (3.17), A is Top $\mathrm{S}_{\Gamma}$-act .

We denote the complement of $V_{\Gamma}(\mathrm{N})$ in $\tau(\mathrm{M})$ for any $\mathrm{S}_{\Gamma}$-subact $\mathrm{N}$ of $\mathrm{M}$ by $D_{\Gamma}(\mathrm{N})$, i.e. $D_{\Gamma}(\mathrm{N})=\operatorname{Spec}_{\Gamma}(\mathrm{M}) \backslash V_{\Gamma}(\mathrm{N})$. Note that $D_{\Gamma}(m)=D_{\Gamma}(\mathrm{S} \Gamma m)$ for every $m \in \mathrm{M}$.

\subsection{Proposition.}

If $\mathrm{M}$ is a multiplication $\mathrm{S}_{\Gamma}$-act, then the following conditions hold:

i. $D_{\Gamma}(m) \cap D_{\Gamma}(n)=D_{\Gamma}(m * n)$ for any $m, n \in \mathrm{M}$.

ii. Let $\mathrm{N} \subset \mathrm{M}$ with every proper $\mathrm{S}_{\Gamma}$-subact of $\mathrm{M}$ is the intersection of primes. If $D_{\Gamma}(\mathrm{N})$ $=\varnothing$, then $\mathrm{N}$ is $\Gamma$-nilpotent .

Proof:(i) Let $m, n \in \mathrm{M}$. Then $\mathrm{S} \Gamma m=\mathrm{A} \Gamma \mathrm{M}$ and $\mathrm{S} \Gamma n=\mathrm{B} \Gamma \mathrm{M}$ for some $\Gamma$-ideals $\mathrm{A}$ and $\mathrm{B}$ of S. By Corollary (3.16), $D_{\Gamma}(m) \cap D_{\Gamma}(n)=$ $D_{\Gamma}(\mathrm{A} \Gamma \mathrm{M}) \cap D_{\Gamma}(\mathrm{B} \Gamma \mathrm{M})=\left[\operatorname{Spec}_{\Gamma}(\mathrm{M}) \backslash V_{\Gamma}(\mathrm{A} \Gamma \mathrm{M})\right]$ $\mathrm{n}\left[\operatorname{Spec}_{\Gamma}(\mathrm{M}) \backslash \mathrm{V}_{\Gamma}(\mathrm{B} \Gamma \mathrm{M})\right]=\operatorname{Spec}_{\Gamma}(\mathrm{M}) \backslash\left[V_{\Gamma}(\mathrm{A} \Gamma \mathrm{M})\right.$ $\left.\mathrm{U} V_{\Gamma}(\mathrm{B} \Gamma \mathrm{M})\right]=\operatorname{Spec}_{\Gamma}(\mathrm{M}) \backslash V_{\Gamma}((\mathrm{A} \Gamma \mathrm{B}) \Gamma \mathrm{M})$ $=\operatorname{Spec}_{\Gamma}(\mathrm{M}) \backslash V_{\Gamma}(m * \mathrm{n})=D_{\Gamma}(m * n)$.

(ii) Let $D_{\Gamma}(N)=\emptyset$. Then, $\operatorname{Spec}_{\Gamma}(\mathrm{M}) \backslash V_{\Gamma}(\mathrm{N})=\emptyset$ thus $\operatorname{Spec}_{\Gamma}(\mathrm{M})=V_{\Gamma}(\mathrm{N})$ and hence $V_{\Gamma}(\mathrm{N})=V_{\Gamma}(\theta)$. By Proposition (3.3)(v), N= $\theta$. Therefore, $N$ is a $\Gamma$-nilpotent.

\subsection{Proposition.}

Let $\mathrm{M}$ be a $\mathrm{S}_{\Gamma}$-act. Then the sets $\left\{D_{\Gamma}\left(m_{i}\right): i \in I\right\}$ forms a base of the gamma act topology on $\mathrm{M}$.

Proof: Any nonempty open set in the gamma act topology contains $D_{\Gamma}(\mathrm{K})$ for some $\mathrm{S}_{\Gamma}$-subact $\mathrm{K}$ of $\mathrm{M}$. Now, any such $\mathrm{K}=\mathrm{U}_{i \in I}\left\{m_{i}\right\}$ , $m_{i} \in \mathrm{K}$. Then, $D_{\Gamma}(\mathrm{K})=D_{\Gamma}\left(\cup_{i \in I} m_{i}\right)=\operatorname{Spec}_{\Gamma}(\mathrm{M}) \backslash$ $V_{\Gamma}\left(\mathrm{U}_{i \in \mathrm{I}} m_{i}\right)=\operatorname{Spec}_{\Gamma}(\mathrm{M}) \backslash \bigcap_{i \in \mathrm{I}} V_{\Gamma}\left(m_{i}\right)=\mathrm{U}_{i \in I} D_{\Gamma}\left(m_{i}\right)$.

\subsection{Definition}

(Erdogan, 2003) Let $\mathcal{A}=\left\{A_{i}: i \in I\right\}$ be a collection of sets. Then $\mathcal{A}$ is said to have the finite intersection property if for every finite collection $\left\{A_{1}, \ldots, A_{n}\right\}$ of $\mathcal{A}$, we have that $\bigcap_{i=1}^{n} A_{i} \neq \varnothing$.

\subsection{Theorem}

(Erdogan, 2003) A topologicalspace $\mathrm{X}$ is compact if and only if for every collection of closed sets $\mathcal{A}$ of $\mathrm{X}$, with $\mathcal{A}$ has the finite intersection property then, $\bigcap_{A \in \mathcal{A}} A \neq \emptyset$.

\subsection{Theorem.}

If $\mathrm{M}$ is finitely generated multiplication $\mathrm{S}_{\Gamma}$-act, then $\operatorname{Spec}_{\Gamma}(\mathrm{M})$ is compact.

Proof: Let $\left\{V_{\Gamma}\left(N_{i}\right): i \in \mathrm{I}\right\}$ be any collation of closed subsets of $\operatorname{Spec}_{\Gamma}(\mathrm{M})$ where $N_{i}$ is a $\mathrm{S}_{\Gamma}$-subact of $\mathrm{M}$ for each $i \in \mathrm{I}$ such that $\bigcap_{i \in I} V_{\Gamma}\left(\mathrm{N}_{i}\right)=\varnothing$. Thus, by Theorem (3.3)(vi), $\bigcap_{i \in I} V_{\Gamma}\left(\mathrm{N}_{i}\right)=V_{\Gamma}\left(\mathrm{U}_{i \in I} \mathrm{~N}_{i}\right)=V_{\Gamma}\left(\mathrm{U}_{i \in I}\left[\mathrm{~N}_{i}: \mathrm{M}\right] \Gamma \mathrm{M}\right)$ and hence $V_{\Gamma}\left(\bigcup_{i \in I}\left[\mathrm{~N}_{i}: \mathrm{M}\right] \Gamma \mathrm{M}\right)=\emptyset$. Now, suppose that $\mathrm{M} \neq \mathrm{U}_{i \in I}\left[\mathrm{~N}_{i}\right.$ : $\left.\mathrm{M}\right] \Gamma \mathrm{M}$ then $V_{\Gamma}(\mathrm{M})$ $\neq V_{\Gamma}\left(\mathrm{U}_{i \in I}\left[\mathrm{~N}_{i}: \mathrm{M}\right] \Gamma \mathrm{M}\right)$. This implies that $\varnothing$ $\neq V_{\Gamma}\left(\mathrm{U}_{i \in I}\left[\mathrm{~N}_{i}: \mathrm{M}\right] \Gamma \mathrm{M}\right)$, a contradiction. Thus, $\mathrm{U}_{i \in I}\left[\mathrm{~N}_{i}: \mathrm{M}\right] \Gamma \mathrm{M}=\mathrm{M}$. Since $\mathrm{M}$ is finitely generated, there exists a finite subset I'of I such that $\mathrm{M}=\bigcup_{i \in I^{\prime}}\left[\mathrm{N}_{i}: \mathrm{M}\right] \Gamma \mathrm{M}$. Therefore, $\bigcap_{i \in I^{\prime}} V_{\Gamma}\left(\mathrm{N}_{i}\right)=V_{\Gamma}\left(\bigcup_{i \in I^{\prime}} \mathrm{N}_{i}\right)=V_{\Gamma}\left(\bigcup_{i \in I^{\prime}}\left[\mathrm{N}_{i}: \mathrm{M}\right] \Gamma \mathrm{M}\right.$ $=\varnothing$. Which contradicts the finite intersection property. By Theorem (3.22), $\operatorname{Spec}_{\Gamma}(\mathrm{M})$ is compact.

Now, we study some of the separation axioms and the density of topological gamma acts.

\subsection{Definition.}

Let $\mathrm{M}$ be a $\mathrm{S}_{\Gamma}$-act and $\mathrm{X}$ be a nonempty subset of $\operatorname{Spec}_{\Gamma}(\mathrm{M})$. Then the Jacobson radical of $X$ is the intersection of all prime $\mathrm{S}_{\Gamma}$-subacts of $\mathrm{M}$ which belong to $\mathrm{X}$ and denoted by $J_{\Gamma}(\mathrm{X})$. We denote the closure of a subset $\mathrm{X}$ of $\operatorname{Spec}_{\Gamma}(\mathrm{M})$ by $\overline{\mathrm{X}}$.

\subsection{Theorem.}

Let $\mathrm{M}$ be a Top $\mathrm{S}_{\Gamma}$-act. Then, $\overline{\mathrm{X}}=V_{\Gamma}\left(\left(J_{\Gamma}(\mathrm{X})\right)\right.$. 
Proof: Let $V_{\Gamma}(\mathrm{N})$ be a closed set containing $\mathrm{X}$, and $\mathrm{P}$ be a prime $\mathrm{S}_{\Gamma}$-subact in $\mathrm{X}$. Then $\mathrm{N} \subseteq \mathrm{P}$, and hence $\mathrm{N} \subseteq J_{\Gamma}(\mathrm{X})$.Thus, $V_{\Gamma}\left(J_{\Gamma}(\mathrm{X})\right) \subseteq V_{\Gamma}(\mathrm{N})$. Since $\mathrm{X} \subseteq V_{\Gamma}\left(J_{\Gamma}(\mathrm{X})\right)$, then $V_{\Gamma}\left(J_{\Gamma}(\mathrm{X})\right)$ is the smallest closed subset of $\operatorname{Spec}_{\Gamma}(\mathrm{M})$ containing X. So, $\bar{X}=V_{\Gamma}\left(\left(J_{\Gamma}(\mathrm{X})\right)\right.$.

Recall that a topological space is a $\mathrm{T}_{0}$-space if and only if the closures of distinct points are distinct. A subset $\mathrm{A}$ of a topological space $X$ is called dense in $X$ if $\bar{X}=A$. (Erdogan 2003 \& Oner 2020)

\subsection{Corollary.}

If $(\theta) \in X$, then $X$ is dense

in $\operatorname{Spec}_{\Gamma}(\mathrm{M})$.

Proof: By Theorem (3.25), $\overline{\mathrm{X}}=V_{\Gamma}\left(\left(_{\Gamma}(\mathrm{X})\right)\right.$ $=V_{\Gamma}(\theta)=\operatorname{Spec}_{\Gamma}(\mathrm{M})$. Hence, $\mathrm{X}$ is dense.

\subsection{Corollary.}

$\operatorname{Spec}_{\Gamma}(\mathrm{M})$ is a $\mathrm{T}_{0}$-space

for every Top $\mathrm{S}_{\Gamma-\text { act }} \mathrm{M}$.

Proof: Let $N_{1}$ and $N_{2}$ be two distinct points of $\operatorname{Spec}_{\Gamma}(\mathrm{M})$. Then, $\overline{\left\{N_{1}\right\}}=V_{\Gamma}\left(N_{1}\right) \neq V_{\Gamma}\left(N_{2}\right)=\overline{\left\{N_{2}\right\}}$.

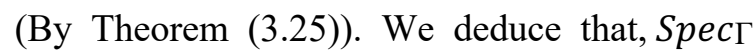
(M) is a $\mathrm{T}_{0}$-space.

A topological space $X$ is a $T_{1}$-space if and only if all points of $X$ are closed in $X$ (i.e., given any $\mathrm{x}$ in $\mathrm{X}$, the singleton set $\{\mathrm{x}\}$ is a closed set. (Erdoğan 2003\&Öner 2020).

\subsection{Theorem.}

Let $\mathrm{M}$ be a $\mathrm{S}_{\Gamma}$-act. Then $\operatorname{Spec}_{\Gamma}$

(M) is $T_{1}$-space if and only if each prime $\mathrm{S}_{\Gamma}$-subact in $\operatorname{Spec}_{\Gamma}(\mathrm{M})$ is maximal.

Proof: $(\Leftarrow) \operatorname{Let}\{\mathrm{P}\} \subseteq \operatorname{Spec}_{\Gamma}(\mathrm{M})$. Then, $\quad \overline{\{P\}}=V_{\Gamma}$ $\left(\left(J_{\Gamma}(\{\mathrm{P}\})\right)=V_{\Gamma}(\mathrm{P})\right.$. Since $\{\mathrm{P}\}$ is maximal. Thus, $\overline{\{P\}}=V_{\Gamma}(\mathrm{P})=\{\mathrm{P}\}$.

$(\Longrightarrow)$ Let $\mathrm{P}$ be a prime $\mathrm{S}_{\Gamma}$-subact of $\mathrm{M}$. By hypothesis $\{\mathrm{P}\}$ is a closed subset of $\operatorname{Spec}_{\Gamma}(\mathrm{M}) . \quad$ Thus $\quad V_{\Gamma}(P)=V_{\Gamma}$
$\left(\left(J_{\Gamma}(\mathrm{P})\right)=\overline{\{P\}}=\mathrm{P}\right.$. Hence, $\mathrm{P}$ is maximal in $\operatorname{Spec}_{\Gamma}(\mathrm{M})$.

Recall, if $\mathrm{N}$ is a prime $\mathrm{S}_{\Gamma}$-subact of $\mathrm{S}_{\Gamma}$-act $\mathrm{M}$, then [N:M] is a prime $\Gamma$-ideal of $\mathrm{S}$. This idea motivates us to introduce and study the following mapping that gives a relationship between $\operatorname{Spec}_{\Gamma}(\mathrm{M})$ and $\operatorname{Spec}_{\Gamma}(\mathrm{S})$. Before this we need the following Lemma.

\subsection{Lemma.}

Let $\mathrm{S}$ be a commutative $\Gamma$ monoid and $\mathrm{M}$ be a $\mathrm{S}_{\Gamma}$-act. Then [SГP:M] $=\mathrm{S} \Gamma[\mathrm{P}: \mathrm{M}]$ for all $\mathrm{S}_{\Gamma}$-subact $\mathrm{P}$ of $\mathrm{M}$.

Proof: Clear.

\subsection{Definition.}

Let $\mathrm{S}$ be a $\Gamma$-monoid and $\mathrm{M}$ be a $\mathrm{S}_{\Gamma}$-act. Define a mapping $\psi: \operatorname{Spec}_{\Gamma}(\mathrm{M}) \rightarrow$ $\operatorname{Spec}_{\Gamma}(\mathrm{S})$, by $\mathrm{P} \mapsto[\mathrm{P}: \mathrm{M}]$ for all $\mathrm{P} \in \operatorname{Spec}_{\Gamma}(\mathrm{M})$.

Clearly, by Lemma (3.30) $\psi$ is well-defined and $\mathrm{S}_{\Gamma}$-homomorphism. The next Proposition present some properties of the mapping $\psi$.

\subsection{Proposition.}

Let $\mathrm{S}$ be a $\Gamma$-monoid, and $\mathrm{M}$ be $\mathrm{a}$ multiplication $\mathrm{S}_{\Gamma}$-act, then

i. If $\mathrm{M}$ is faithful, then mapping $\psi$ is surjective.

ii. The mapping $\psi$ is injective.

Proof:(i) Let $\mathrm{P} \in \operatorname{Spec}_{\Gamma}(\mathrm{S})$. By Proposition (2.4), РГM is a prime $\mathrm{S}_{\Gamma}$-subact. Now, $\psi(\mathrm{P} \Gamma \mathrm{M})=[\mathrm{P} \Gamma \mathrm{M}: \mathrm{M}]=\mathrm{P}$.

(ii) Let $\mathrm{N}_{1}, \mathrm{~N}_{2} \in \operatorname{Spec}_{\Gamma}(\mathrm{M})$ with $\psi\left(\mathrm{N}_{1}\right)=\psi\left(\mathrm{N}_{2}\right)$. Then, $\left[\mathrm{N}_{1}: \mathrm{M}\right]=\left[\mathrm{N}_{2}: \mathrm{M}\right]$ and hence $\left[\mathrm{N}_{1}: \mathrm{M}\right] \Gamma \mathrm{M}$ $=\left[\mathrm{N}_{2}: M\right] \Gamma$ M. So, $\mathrm{N}_{1}=\mathrm{N}_{2}$.

Thus, the mapping $\psi$ plays an important role in studying algebraic properties of the $\mathrm{S}_{\Gamma}$-act $\mathrm{M}$ when we have a related topology. For an example, if $\mathrm{M}$ is a faithful multiplication $\mathrm{S}_{\Gamma}$-act, then $\operatorname{Spec}_{\Gamma}(\mathrm{S})$ and $\operatorname{Spec}_{\Gamma}(\mathrm{M})$ are homeomorphic, and hence we can transfer some of known topological properties of $\operatorname{Spec}_{\Gamma}(\mathrm{M})$ to $\operatorname{Spec}_{\Gamma}(\mathrm{S})$. 


\section{ACKNOWLEDGEMENTS}

The authors would like to thank A1Mustaqbal University College and AlZahraa University for Women for giving them the opportunity time and scientific support for completing this research.

\section{References}

Abbas, M. \& Faris, A. (2016) Gamma"Acts. International Journal of Advanced Research, 4 (6) : 1592-1601.

Abbas, M. \& Jubeir, S. (2020) Idempotent" and Pure Gamma"Subacts of multiplication Gamma Acts. Materials Science and Engineering, 871(1): 1-13.

Abbas, M. \& Jubeir, S. (2020) The product of gamma subacts of multiplication gamma act. Proceedings of Internationa conference of modern application on information and communication technology. Babylon, Iraq.

Anjaneyulu, A.; Gangadhara, A. \& Madhusudhana, D. (2011) Prime Radicals In $\Gamma$-Semigroups". International Journal of Mathematical and Engineering, 138 (3): 1250-1259.
Anjaneyulu, A.; Gangadhara, A. \& Madhusudhana, D. (2012) Duo Chained $\Gamma$-semigroups. International Journal of Mathematical Sciences, Technology, and Humanities, 50 (2): 520-533.

Erdoğan, S. (2003) Functional Analysis." Springer-Verlag, New Yourk. Pp.241.

Kamal, A. (2016) Gamma"Acts. M.Sc. thesis, University of Al-Mustansiriyah, Baghdad, Iraq.

Öner, T. (2020) Rarely convergent sequences in topological spaces. Kuwait Journal of Science, 47 (3):2-13.

Sen, M. (1981) On $\Gamma$-semigroups". Proceedings of Internationa Conference on Algebra and its Applications. Decker Publication, New York.

Sen, M. \& Saha,K. (1986) On $\Gamma$ semigroup. Bull. Calcutta Math. ,78 (3): 180-186.

$\begin{array}{ll}\text { Submitted } & : 13 / 07 / 2020 \\ \text { Revised } & : 10 / 09 / 2020 \\ \text { Accepted } & : 13 / 09 / 2020 \\ \text { DOI } & : 10.48129 / \text { kjs.v48i2.10147 }\end{array}$

